\title{
Thermal Expansion of Solids
}

\section{UNITED STATES DEPARTMENT OF COMMERCE}

\author{
NATIONAL BUREAU OF STANDARDS
}




\section{Published Recently \\ Density of Solids and Liquids}

Eleven methods for determinations of the densities of solids and liquids are described in this new Circular. These include hydrostatic weighing, picnometer, flotation, hydrometer, falling drop, balanced column, Boyle's law, electromagnetic, elastic helix, ice calorimeter and volumetric methods. The accuracy or reliability of various procedures is also given.

Order NBS Circular 487, Density of Solids and Liquids, 29 twocolumn pages, illustrated, from the Superintendent of Documents, U. S. Government Printing Office, Washington 25, D. C. Price: domestic, 20 cents. 


\section{Thermal Expansion of Solids}

by Peter IIidnert and Wilmer Souder

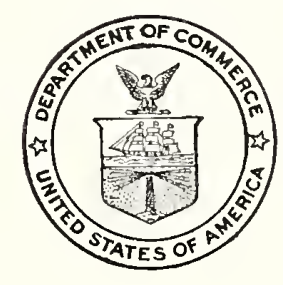

National Bureau of Standards Circular 486

Issued March ${ }_{0}$, 1950

For sale by the Superintendent of Documents, U. S. Government Printing Office, Washington 25, D. C. Price 20 cents 


\section{Preface}

Thermal expansion is one of the fundanental properties of materials that is important in seience and industry. The problems in which the thermal expansion of materials must be recognized are as varied as our industries.

This Circular is issued to supply a demand for information about various mothods for determinations of thermal expansion of solids. Related topies sueh as relations between thermal expansion and chemical composition of materials are also discussed in the Cirenlar.

Three types of themostats (differential expansion, bimetallic flexure, and fluid expansion) used in various applications, are discussed.

At various times during the past four decades, this Bureau has published the results of investigations on the thermal expansion of various materials. A list of these publications will be sent free of charge to anyone interested, upon request.

E. U. Condox, Director. 


\section{Contents}

Preface Page

I. Introduction _...

II. Types of Thermal-Expansion Apparatus _..._._.

1. Precision micrometric method

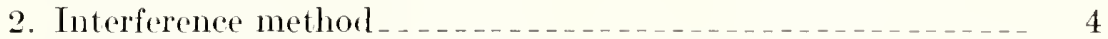

3. Fused-quartz tube and dial-indicator method _.......... 5

4. Autographic optical-lever method _................ 6

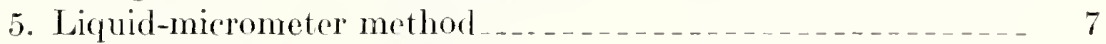

6. Induetion-furnace and dial-indicat or method _._._._. 8

7. Capacitance methot _._.

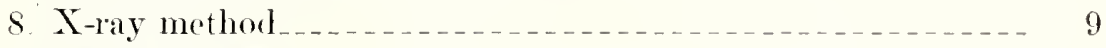

9. Density method _._._.

10. Methods for determinations of volume changes in metals and alloys during casting _............................ 13

(a) Liquid shrinkage............................ 14

(b) Solidification range $\ldots \ldots \ldots \ldots \ldots \ldots$

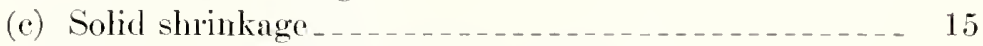

(d) Specific rolume-temperature curves _............ 17

(e) Other methods ............................ 18

III. Data on Thermal Expansion $\ldots \ldots \ldots \ldots \ldots \ldots \ldots \ldots \ldots \ldots$

IV. Relations Between Thermal Expansion and Other Properties_____ 20

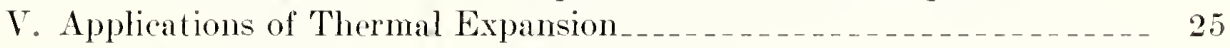

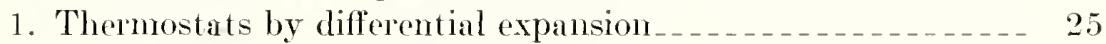

2. Thermostats by bimetallic flexure _..._._.

3. Thermostats by fluid expansion _..................... 27

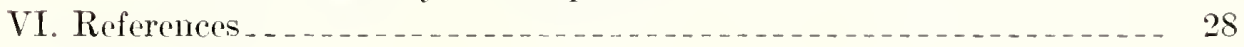





\title{
Thermal Expansion of Solids
}

\author{
by Peter Hidnert and Wilmer Souder
}

\begin{abstract}
This Circular deseribes 10 methods for determinations of therual expansion of solids. The procedures used in determining expansion equations and conflicients of expansion of materials are given. Relations between thermal expansion, temperature, ehenical composition, density, compressibility, specific heat, melting point, atomic weight, and other properties of materials are indicated. The problems in which the thermal expansion of materials must be recognized are as varied as our inchustries. One of the important applications of thermal expansion is in thernostats that are described in the publication.
\end{abstract}

\section{Introduction}

One of the frecuently measured physical properties of materials is thermal expansion. Practically all materials undergo a cliange of dimensions when they are heated or cooled. For isotropie bodies, the expansion or contraction is the same in all directions, but in anisotropic bodies the expansion or eontraction is dependent on direction.

Determinations of dimensional changes of materials, of cocfleients of linear and cubical expansion, and of the temperatures and magnitudes of dimensional ehanges during transformations at constant temperature and with slow or relatively rapid heating and cooling rates (inchuling quenching) are important in science and industry. Dilatometric methods have an advantage over the thermal method (temperaturetime cooling curves) in investigating transformations, for the temperatures may be passed through slowly or quickly or the sample may be held at a given temperature for any length of time in order to attain equilibrium and the heating or cooling then resumed. Various types of thermalexpansion apparatus are used for these determinations.

The change in length that takes place when a solid body is leated depends upon the original length of the body and the temperature lange over which it is heated. The observation of this change is meaningless unless it is related to the length of the body and the temperature range. The relation between these factors known as the coefficient of linear thermal expansion has been defined in a number of ways.

The average coefficient of linear expansion is defined as

$$
{ }_{t_{1}} a_{t_{2}}=\frac{L_{2}-L_{1}}{L_{0}\left(t_{2}-t_{1}\right)}=\frac{\Delta L}{L_{0} \cdot \Delta t},
$$

where $t_{1} a_{t_{2}}$ is the average coefficient of expansion between temperatures $t_{1}$ and $t_{2}, L_{1}$ and $L_{2}$ are the lengths at $t_{1}$ and $t_{2}$, respectively, and $L_{0}$ is the length at a reference temperature. This reference temperature may be $0^{\circ} \mathrm{C}$, room temperature, or any other convenient temperature. The authors prefer to use $0^{\circ} \mathrm{C}$ for the reference temperature. If it is not convenient to obtain the length at $0^{\circ} \mathrm{C}$, the length at room temperature is used. The difference introduced in the latter rase is negligible for the average coefficient of linear expansion.

The instantaneous coeflieient of lincar expansion or coefficient of expansion at any temperature, $t$, may be defined as

$$
a_{t}=\lim _{t_{1} \rightarrow t_{2}} \frac{L_{2}-L_{1}}{L_{0}\left(t_{2}-t_{1}\right)}=\frac{d L}{L_{0}(d t)},
$$

where $a_{t}$ is the instantaneous coeffieient of linear expansion at temperature $t$.

If $L_{0}$ is the length of a solid body at $0^{\circ} \mathrm{C}$, then its length at any temperature $t^{\circ} \mathrm{C}$ may be represented by the empirieal equation

$$
L_{t}=L_{0}\left(1+a t+b t^{2}+\ldots\right),
$$

where $a$ and $b$ are constants, depending upon the material. In most cases, these constants $a$ and $b$ are positive, for bodies usually expand at a faster rate as the temperature increases. For a short range of temperature, the cquation $L_{t}=L_{0}(1+a t)$ representing a straight line may be used instead of eq 3 representing a enrve. When a molecular change (transformation) oceurs on heating or cooling a body, its length may not be aceurately represented by a first, second, or third degree 
equation. In such eases, it may be desirable to obtain two equations, one for the range below the transformation temperature or point of inflection, and the other equation for the range above the transformation temperature.

The instantaneous roefficient of linear expansion nay also be derived by differentiation of eq 3 , and represented as follows:

$$
a_{t}=\frac{a+2 b t+\ldots,}{L_{0}}
$$

where $a$ and $b$ are the same constants used in eq 3 . The instantaneous coefficient of expansion at $0^{\circ}$ $\mathrm{C}$ is $a / L_{0}$.

A rhange in vohume that takes place when a solid body is heated may be treated in a similar manner. The following equations correspond to the previous equations relating to linear themal expansion:

$$
\begin{gathered}
t_{1} \alpha_{l_{2}}=\frac{\Gamma_{2}-\Gamma_{1}}{V_{0}\left(t_{2}-t_{1}\right)}=\frac{\Delta I}{V_{0}(\Delta t)} \\
\alpha_{t}=\lim _{t_{1}-t_{2}} \frac{\Gamma_{2}-T_{1}}{\Gamma_{0}\left(t_{2}-t_{1}\right)}=\frac{d V}{V_{0}(d t)} \\
V_{t}=\Gamma_{0}\left(1+\alpha t+\beta t^{2}+\ldots .\right) \\
\alpha_{t}=\frac{\alpha+2 \beta t+\ldots}{V_{0}}
\end{gathered}
$$

In eq 5 to 8

${ }_{t_{1}} \alpha_{t_{2}}=$ average coefficient of cubical thermal expansion between temperatures $t_{1}$ and $t_{2}$

$V_{1}=$ volume at $t_{1}$

$T_{2}=$ volume at $t_{2}$

$\Gamma_{0}=$ volume at a reference temperature (In eq 7 , volume at $0^{\circ} \mathrm{C}$ )

$\alpha_{\ell}=$ instantaneous coefficient of cubical thermal expansion at any temperature $t^{\circ}$

$\Gamma_{t}=$ volume at any temperature $t^{\circ}$

$\alpha$ and $\beta=$ constants depending upon the material.

The average coefficient of cubical thermal expansion of an isotropic body between $t_{1}$ and $t_{2}$, is represented by the equation

$$
{ }_{t_{1}} \alpha_{t_{2}}=3{ }_{t_{1}} a_{t_{2}}+3{ }_{t_{1}} a^{2} t_{2}\left(t_{2}+t_{1}\right)+{ }_{t_{1}} a_{t_{2}}^{3}\left(t_{2}^{2}+t_{2} t_{1}+t_{1}^{2}\right)
$$

When $t_{1}=0^{\circ}$, eq 9 may be expressed as

$$
{ }_{0} \alpha_{t}=3_{0} a_{t}+3_{0} a_{t}^{2} t+{ }_{0} a_{t}^{3} t^{2},
$$

where $\alpha_{t}$ and on, represent the average cocflicient of cubical expansion and the average coeffeient of linear expansion, respectively, between $0^{\circ}$ and $t^{\circ}$. As the second and the third terms of eq 9 and 10 are usually negligible, they reduce to

$$
\begin{aligned}
t_{1} \alpha_{l_{2}} & =3_{t_{1}} a_{t_{2}} \\
{ }_{0} \alpha_{t} & =3_{0} a_{\imath}
\end{aligned}
$$

\section{Types of Thermal-Expansion Apparatus}

Ten methods for measurement of thermal expansion are described in this Cireular.

\section{Precision Micrometric Method}

The National Burean of Standarels uses micrometrie thermal-expansion apparatus for the most precise work on the linear thermal expansion of solids between $-1500^{\circ} \mathrm{C}$ and $+1,0000^{\circ} \mathrm{C}$. This apparatus is of two types: (1) The artype heating chamber, shown at the left in figure 1 , in which the sample is surounded by air or an inert gas, anel (2) the stirxed-liquid bath, shown at the right in figure 1, in which the sample is surounded by a suitable liquid.

In both types of apparatus electrie heatine is used. Thermocouples and a potentiometer are used for measuring temperatures. For determinations at low temperatures, cooling is secured in the stirred-liquid bath by expanding compressed air from a liquid-air interchanger through coils immersed in the bath.

The positions of the ends of the sample in the air chamber are intieated by fine wires $(0.001$ or $0.002 \mathrm{in}$. in diam) weighted and hanging vertically from the ends of the sample through slots in the bottom of the chamber. Two micrometer microscopes, mounted horizontally on a traveling comparator and separated by a lateral distance approximately equal to the length of the sample (10 to $50 \mathrm{~cm}$ ), are used to measure the length changes, as inflirated by the changes in separation of these wires. In the stirred liquid bath, tungsten wires $(0.001 \mathrm{in}$. in diam) in contact with the ends of the sample, extend from a fixed horizontal bar above the sample to hinged fingers, inserted beneath the ends of the sample as indicated in figure 2. Hore the length ehanges of the sample are proportional to the changes in the distances between the wiles in the plane of the microseopes.

The sample is in the form of a straight rod or bar of miform cross section. The usual length is $300 \mathrm{~mm}$, and the diameter (or diagonal if the rod has a rectangular cross section) is 5 to $10 \mathrm{~mm}$. The rod is prepared with cylindrical ends having radii of curvature rqual to one-half the length of the rod, so that the measured length will not change for shight vertical rotations about its center. Provision has been made for handling samples of other lengths and diameters. The limits of length are the length of the furnace for long rods $(50 \mathrm{~cm})$ and the limit of contact approach of the two 
relicle frames mored by the mieroseope micromcters.

The air funare has control rheostats for cach side and end of the heatine chamber. The extrinal heat loss from these rheostats is redured by using a transformer for the lower temperatures.

With these types of apparatus it is essential that the position of the samples be maintained horizontally during the determinations. A further requirement for the stined liquid bath is that the readings be mate at a known distance above cach end of the smmple, and that the ratio of distanees (level of observation to upper supports of wiles and onds of sample to upper supports of wines) be known and maintained.

The atrangement of the furmates, stambard bar, and comparator is shown in figure 1. The air type heatinge chomber or funace, is shown at the extreme left of the figure. A smaller a ir fumace is shown at the right of the laree furmace. The standard bar of fused quartz and the mierometer comparator appear in front of the window. 'The interehanger and stirred liquid bath are partially

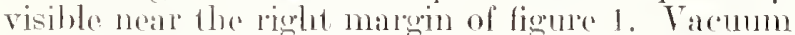
bottles filled with melting ien for maintaining the temperature of the cold junetions at $0^{\circ} \mathrm{C}$ appeal at the right of the two furnteres in this figme. Commections to the potentiomoter al'emade lurongh load-eovered cables and a selertor switeh. Triplejuncetion thermocouples are placed in the air furnaxes. A singhe thermocomple junction in the stired liquirl bath is sufficiont. "The foreed rilculation of the bath liquid by a motor and a propeller maintains uniformity of temperature. Platinum platinum-rhodium ihermoconples are used for the $1,000^{\circ} \mathrm{C}$ air firmace. For the smaller air furnare $\left(600^{\circ} \mathrm{C}\right)$, gold-pilladium platinum-1hodium thermoaouples are used. A eopper-constantan thermocouple is employed in the stirred liquid bath. "The interehanger is of the l'egular" air-liquefying type. The coolad air, compressed 10 about $2,500 \mathrm{lb} / \mathrm{int}^{2}$, is expanded through coils in the stired liquid bath, when temperatures Ledween $+20^{\circ}$ and $-150^{\circ} \mathrm{C}$ are required.

'This mothod for tetermining linear thermal expansion is believed to be the most precise known. Under most farorable conditions, measurements of coefficients of expansion aceurate to 0.1 perecht are possible.

Additional information about this equipment is given in publications by llidnert [1] ${ }^{1}$ and Souder and Hidnert [2]. B̈lueprints giving details of construetion are on file at the National Bureau of standark and may be borrowed upon request.

\section{Interference Method}

When only small samples of material (about $10 \mathrm{~mm}$ or less in length) are available, the Fizeau-

Figures in mackets indicate the literature references at the ond of this Circular.
Pulfrich interference method is especially useful for determinations of linear thermal expansion. The method is also useful for determinations of the linear thermal expansion of crystals or other solids in different directions. The sample is placed vertically between two transparent fusedfuartz plates, ach about $4 \mathrm{~mm}$ thick amel reasonably free from bubbles and other imperfections. The smelares of atch plate should be that within one-filth of a fringe, and shomld be inclined to areh other at an angle of alsout $20^{\prime}$ of are. The sample with the two fusedt-yuartz plates is sot in an cleetrice furnace or cooling chamber for lreating or cooling. When the plates are illuminated normally with momochromatic light, a set of interforenee fringes is producest by the interference of the light reflected between the lower surface of the upper plate and the upper surface of the lower plate, when the angle between these surfaces is slight. The fringes are observed by means of a viewing deviee. Changine the temperature of the simple brings about a change in lengil, whirh ranses the distance between the plates to change with a rorresponding movement of the interference fringes past a reference mark on the lower surface of the upper plate. From the observed displarement of the fringes, the change in length, or linear thermal expansion, an be detemined. The temperature of the sample is detemined with a thomocouple, resistance thermomotere, or interferences thermometer [3]. This mothod may be used at low temperatures and at clevated temperatures to about $1,000^{\circ} \mathrm{C}$.

If the sample is maintained in a vacumm during the determinations, the linear thermal expansion per unit length for a given temperature interval is eomputed from the equation

$$
\frac{\Delta L}{L}=\frac{\lambda N}{2 L},
$$

where $L$ is the initial length of the sample, $\Delta L$ is the change in length or linear thermal expansion, $\lambda$ is the wave length of monochromatic light, and $N$ is the number of fringes that passed the reference mark. If the sample is heated or cooled in air, the following equation should be used:

$$
\frac{\Delta L}{L}=\frac{\lambda N}{2 L}+\frac{A}{L}
$$

where $A$ is the "air correction". This correction varies with the pressure and the temperature of the air. Tables 2 and 3 of Merritt's publication [4] give values of $A / L$ in microns per centimeter for $760 \mathrm{~mm}$ atmospheric pressure, and for various temperatures between $-194^{\circ}$ and $+1,100^{\circ} \mathrm{C}$. The average coefficient of expansion is computed by dividing $\Delta L / L$ by the change in temperature.

Austin [5] stated that the maximum errors of the interference method with his vacuum furmace 
should not be greater than 1 pereent at $300^{\circ} \mathrm{C} \mathrm{or}$ 0.7 pereent at $600^{\circ} \mathrm{C}$, and the probable crrors will be much less than these values. When the sample is heated in an air furmace, the errors may be greater as a result of the uncertainty caused by the presence of an air film between the sample and the interferometer plate and the oxidation or sealing of the sample.

Additional information about the interference method has been published by Peters and Cragoe [6], Merritt [4], and Saunders [7].

Trowbridge [8], Arnulf [9], Sinden [10], Nix and MacNair [11], and Saunders [12] described nethods of photographing fringes.

In 1916 Mleggers [13] indicated how the determination of the exact orlex of interference or the optical measurement of length can be made with the aid of certain wavelengths of neon radiation. In 1919 Peters [14] described the use of the interferometer in the measurement of small dilations by observing fractional orders due to several wavelengths by the mothod described by Megoers. Willey and Fink [15] have recently used this method in determinations of coefficients of expansion of aluminum alloys. The constant attention of the observer and the counting of the interference fringes that pass the reference mark during heating or cooling, or the photographing of fringes are not required. 'The method has been used for many years at the National Bureau of Standards for determinations of the lengths of gage blocks at room temperature.

\section{Fused-Quartz Tube and Dial- Indicator Method}

A fused-quartz-tube thermal-expansion apparatus may be used for determinations of linear thermal expansion for various temperature ranges between $-190^{\circ}$ and $+1,000^{\circ} \mathrm{C}$. This type of apparatus, as improved by Hidnert and Sweeney [16] over a similar type used abroad, is recommended for commercial laboratories where data of the highest precision are not required. With the apparatus it is possible to obtain an accuracy of 2 percent.

Figure 3 shows a fused-ruartz tube closed at the bottom, with a sample $(20 \mathrm{~cm})$ in the tube ready for beating or cooling A movable fused-quartz rod rests on top of the sample and extends above the open end of the tube. The bottoms of the tube and the movable rod are ground concave and the ends of the sample, convex, in order to secure satisfactory contacts. The top of the movable rod, on which a dial indicator rests, is flat. Heating is effected by placing the tube containing the sample in a water or oil bath, or in an electric furnace (fig. 4) extending well above the top of the sample. Low temperatures are secured by using a cooling cabinet or suitable cooling baths, such as liquid air, solid carbon dioxide in a mixture of equal parts of carbon tetrachloride and chloroform, ice and sodimm chloride, and meling ice. A thermocouple, placed inside the fused-cunartz tube near the center

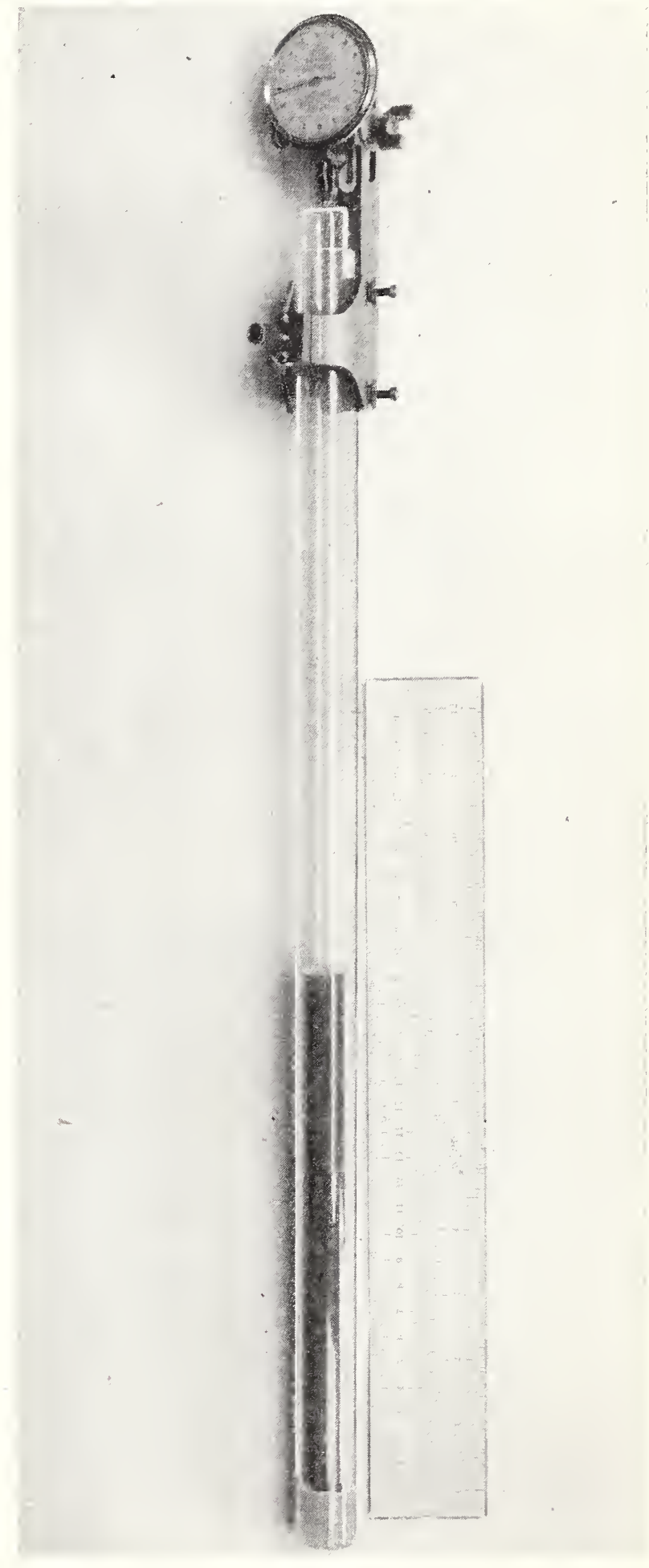

Figure 3. Fused-quartz tube, dial indicator, and sample. 


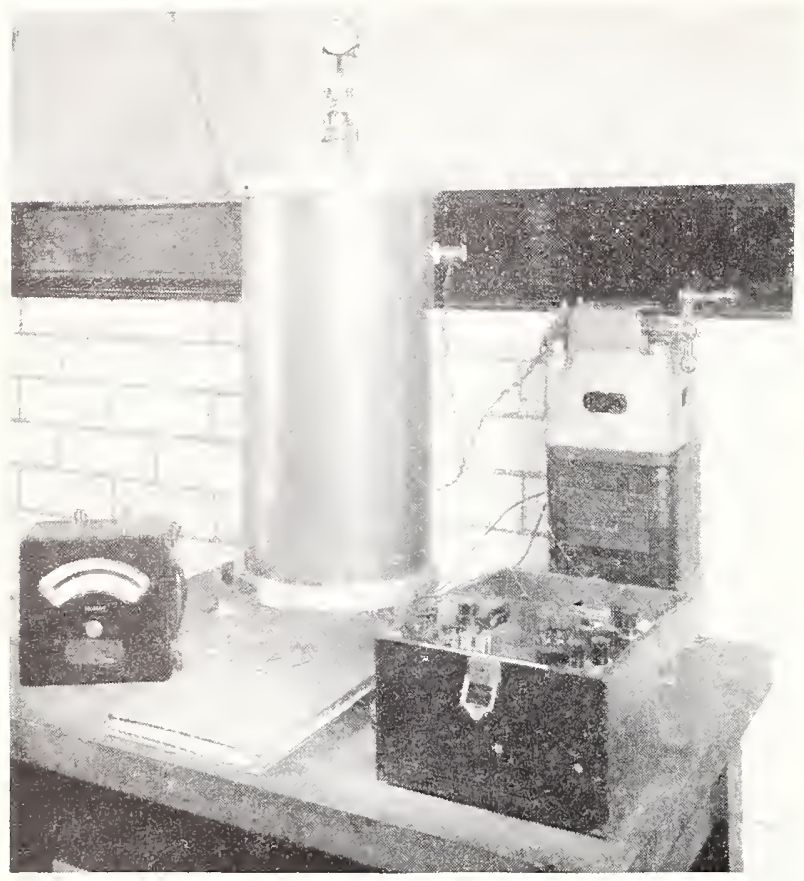

FIGURE 4. Fuscil-quartz tube and dial indicutor thermalexpansion apparatus.

of the sample, indicates the temperature. A dial indieator, fastened near the top of the tube, registers the differential expansion botween the sample and an equivalent length $(20 \mathrm{~cm})$ of fused quartz. A small correction for the linear expansion of fused quartz is male. Prints showing details of this apparatus may be secured from the National Bureau of Standards.
Modifications of the fused-quartz-tube thermalexpansion apparatus for use with shorter samples or with a load on the samples, have been deseribed by Hidnert [17] and by Hidnert and Dickson [18].

Walters and Gensamer [19] modified this type of apparatus so that the expansion of a sample can be determined in a racuum or an inert gas between $-200^{\circ}$ and $+1,000^{\circ} \mathrm{C}$. Kingston $[20]$ modified the apparatus to a recording dilatometer by means of a contact mechanism, transmission shaft, recorder and electronic relay. He also marle provision for the use of various atmospheres.

\section{Autographic Optical-Lever Method}

Sourler, Ifidnert, and Fox [21] designed and construeted an autographic optical-]ever thermalexpansion apparatus for use in commercial laboratories. It was found to give more accurate results than previous apparatus of similar type. With this appratus it is possible to obtain expansion rurves photographically or to observe points on the expansion curves of materials during the progress of the test.

A genernl view of the autographic expansion apparatus is shown in figure 5. The apparatus consists essemially of a furnace, $F$, monnted on a common base with a cannera box, $C$, and a source of illumination, $I$. The back of the camera is provided with a hinged bookform plate holder for S- by 10-in. photographice plates, films, sensitized paper, or a gromnel-glass sereen for photographic or visual observations. The over-all length of the apparatus is approximately $64 \mathrm{in}$., height $19 \mathrm{in.}$ and witth 14 in.

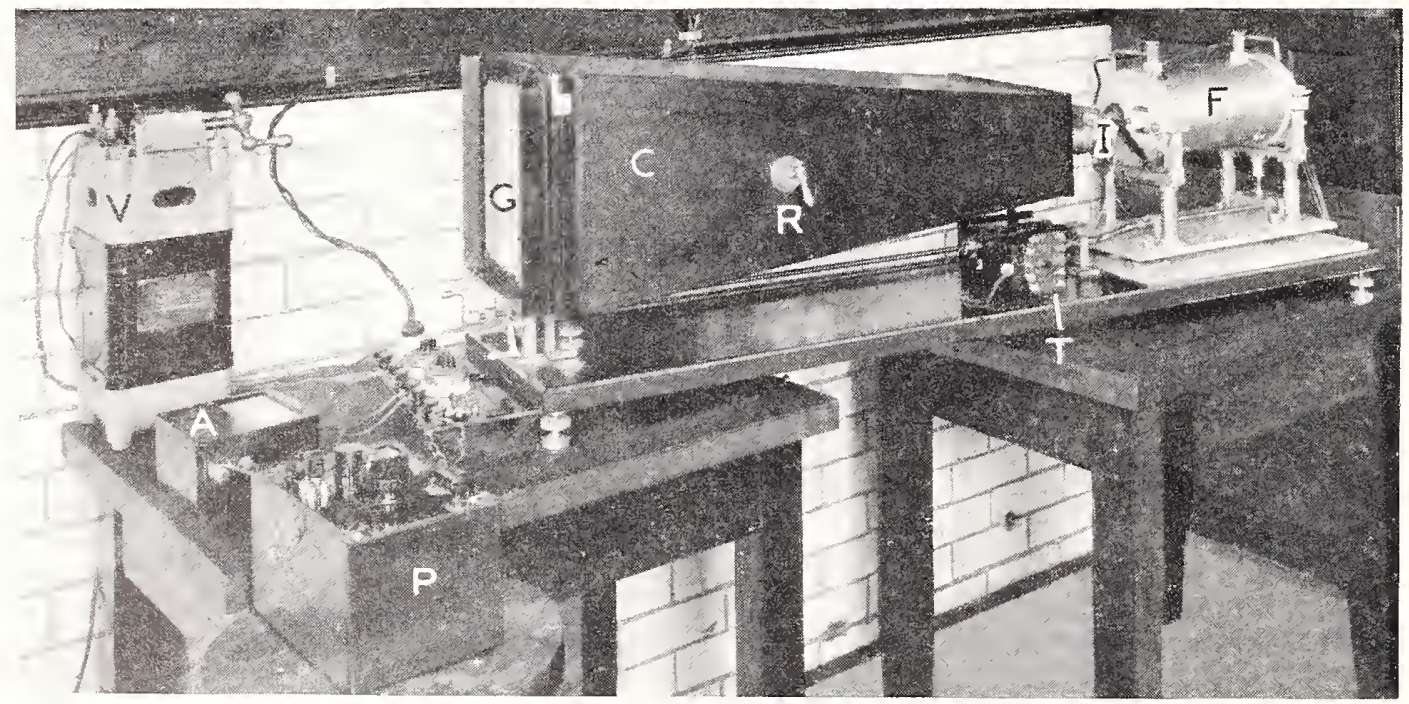

FIGURE 5. Autographic expansion apparatus.

1. Ammeter, $C$, camera box, $F$, furnace; $G$, glass screen; $I$ fllumination; $P$, potentiometer índicator; $R$, intemal reflecting mirror; $T$, transformer; $V$, induction voltage regulator. 


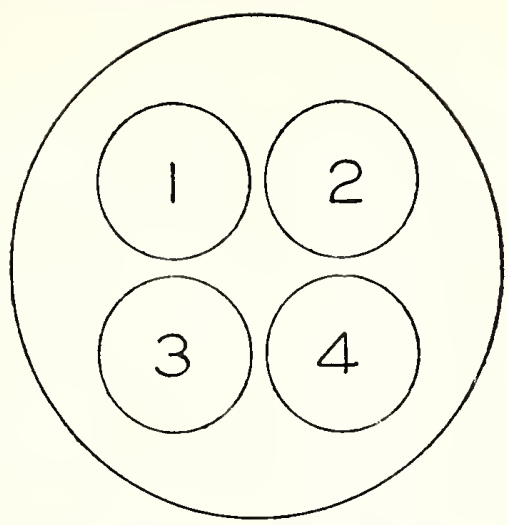

Figure 6. Cross section of alundum cylinder in furnare indicating the holes and the positions of "stationury" axis, temperature axis, sample, and thermocouple.

1, "Stationary" axis; 2, temperature axis; 3, sample (expansion axis); 4 theimocouple.

The observer is locatod at the glass sereen, $G$, of the camera box (fig. 5 ) and is looking toward the furnace.

The following matcrials are inserted in the four horizontal holes of the furnace (fig. 6) :

Hole 1-A long, fused-quartz rod, which represents a "stationary" axis.

Hole 2-A rod of Chromel $A$ having uniform rate of expansion, $150 \mathrm{~mm}$ in length, which represents a temperature axis.

Hole $3-\Lambda$ sample $150 \mathrm{~mm}$ in length.

Hole 4-A Chromel-Alumel thermocouple with 3 junctions, 1 near the center of the sample in hote 3 , and the other junctions near the ends of the sample.

The ends of the rod of Chromel and the sample in holes 2 and 3 , respectively, are pointed. The angle at each pointed end is about $80^{\circ}$.

$A$ fused-quartz plug is in contact with each end of the Chromel rod (temperature axis) and of the sample. The pointed ends of these 4 plugs and of the long, fused-quartz rod ("stationary" axis) extend beyond the ends of the furnace. 'The real of the mirror $M$ (fig. 7 ), held in position by means of a spring, is in contact with the fused-quartz plugs and the "stationary" axis (fused-quartz rod) extending from the left face of the furnace.

Fused-quartz plugs are in contact with the right ends of the Chromel rod and the sample. At each end of these plings there is a $90^{\circ}$ pivot bearing. One end of each of these plugs and one end $\left(90^{\circ}\right.$ pivot bearing) of the "stationary" axis extend beyond the right face of the furmace. Each of these ends is held against an adjustable screw.

When the furnace is heated, the sample and the Chromel rod (temperature axis) expand. The mirror which is in contact with the plugs extending from the sample, Chromel rod (temperature axis) and "stationary" axis therefore moves. The expansion of the sample camses the bottom of the mirror to move and deflect the spot of light upward. The expansion of the Chromel rod (temperature

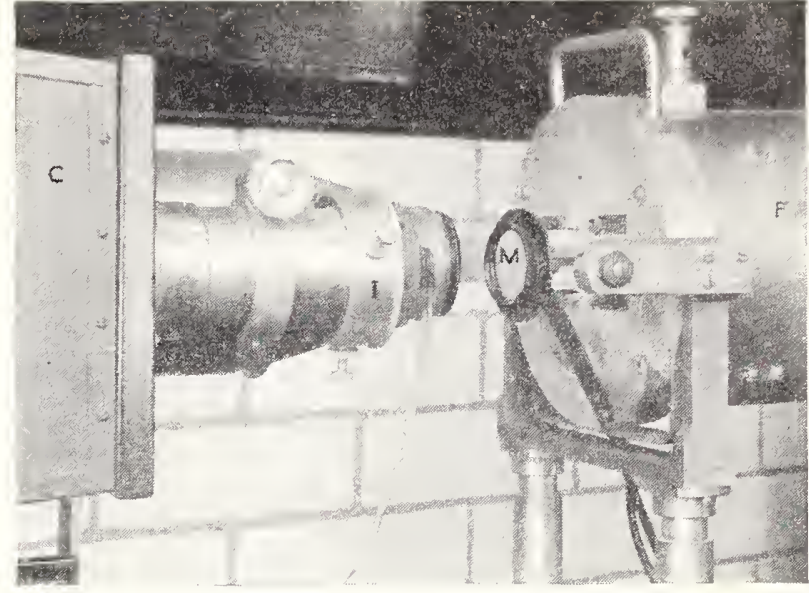

FIGURE 7. Stellite mirror in contact with the fused quartz rorks and the "stationary" axis extending from the left face of the furnare.

$C$, Camera box; $F$, furnace; $I$, illuminator; $M$, optical lever mirror.

axis) causes one side of the mirror to nove and deflect the spot horizontally. The expansion of the fused-quartz plugs, extending on each side of the sample, should balance the expansion of the fusedquartz plugs extending on each side of the Chromel rod (temperature axis), and also the expansion of an equivalent length of the "stationary" axis. A spot of light focused on the mimor and reflected on a glass screen, $G$, or photographic plate, indicates the expansion both of the sample and of the Chromel rod and describes a curve, the resultant of these two expansions vertically and horizontally. The abseissas indieate the expansion of the Chromel rod and may be evaluated to represent temperature. The ordinates represent the expansion of the sample. The curve therefore represents the expansion of the sample versus temperatule.

For materials having coefficients of expansion approximately equal to those for orehinary steel, the error of the autographic expansion apparatus is about 6 pereent for the range from $20^{\circ}$ to $100^{\circ} \mathrm{C}$, and about 3 percent for the range from $20^{\circ}$ to $500^{\circ} \mathrm{C}$. The apparatus is not sufficiently semsitive for tests on low-expanding matcrials. It is not satisfactory at temperatures where softening occurs in the sample or for materials that bencl at elevated temperatures.

Chevenated [22] and other investigators used other forms of the optical lever method for determinations of the linear thermal expansion of materials.

\section{Liquid-Micrometer Method}

A liquicl-micrometer method for determining linear thermal axpansion of solids has been described by Andrew, Rippon, Miller, and Wragg

\section{Thermal Expansion of Solids}


[23]. The sample (in the form of a lollow cylinder $2 \mathrm{in}$. long, $3 / 4 \mathrm{in}$. in diameter with a $\frac{3 / 8}{8}-\mathrm{in}$. hole thromgl the conter) is placed horizontally in a siliea tube of 1 -in. internal cliameter. 'The lueating coil consists of a platinum wire wound around the silica tuber over a lengeth of 9 in. On the emels of the sample, which have loen ground paralled and polished, two siliea disks (also arematrly ground) are placerl. There disks are pressed against the encls of the sample by means of two silica tubes, which transmit dhanges in the length of the sample. One of the latter siliea tubes is butted up against a heary cast-inon hlock, and the other siliea tube is pressed against a moasuring deviece butted to a larere lead blork.

The relative movement of the silica tube is measured by a hydraulic deviee. This consists of a thick sted disk's in. in diameter, having a saucerlike deptession on its fare over which is clamped a thin disk of saw sterel. The space so enclosed is fillerl with colorerl water. A pipe rums through the bark of the sterel disk, commerting this liquid with a horizontal glass tube to which a scale is attacherl. A small leselvoir with a stopeock is also fitted for adjusting the amount of liquid in the system. This liquirl mirrometer is belted to the leat block, so that the thin stred disk is vertical. A strel risk with a flat surface 1 in. in diameter transmits the movement of the siliea tube to the thin sted diaphragm. With a glass tube of about 2-mm bole, the morrment of the meniseus magnifies the displacement of the siliea tube two thousant times. 'The temperature of the sample. is measured by means of a thermocouple placed at the center of the sample. Figure 8 shows a diagrammatic sketeh of the apparatus.

A flexible gas-tight joint is made by means of tubes of thin rublere fixed on the ends of the furnare tubes and them wired to the moving siliea tubes. Through holes drilled in these two silica tubes, gas may be circulated around the sample to prevent oxidation.

It is necessary to calibrate this apparatus with samples of known expansion.

The apparatus was modified by Haughton and Griffiths [24], the changes heing the method of remlering the app tratus autographie, the method of mounting so as to chable adjustment of zero and lesetting to be easily performed, and various minor modifications which simplify its atrangement and use. With this modified dilatometer, using a 2-in. sample, it is possible to record changes of the order of $10^{-6} \mathrm{in}$., although neither the sensitivity nor the aceuracy is normally as high as this.

Because it is under pressure both in the original apparatus and in that modified by Haughton and Griffitlss, the simple is likely to become teformed at high temperatures.

\section{Induction-Furnace and Dial- Indicator Method}

A high-frequency induction funnace was used hy Heindl [25] for determinations of the linear thermal expansion of refractories between $20^{\circ}$ and $1,800^{\circ} \mathrm{C}$. The heat was generated through the medium of a cylindrical graphite muffle, $12 \mathrm{~m}$. long, $6 \mathrm{in.}$ in diameter, and having a wall $1 / 2 \mathrm{in}$. thick. A dial indicator, independent of the furnace, was supported by a framework with fusedquartz tubes for logs.

The arrangement of the sample (about $6 \mathrm{in}$. in length) is indirated in figure 9. This set-up formed a continuous system which expanded and contracted, independently of the furmace. 'Tungsten plates, $7 / 8 \mathrm{in}$. square and $0.015 \mathrm{in}$. thick were placed between the sample and the graphite parts in a reducing atmosphere. The sample was placed within a muflle prepared from zirconium silicate.

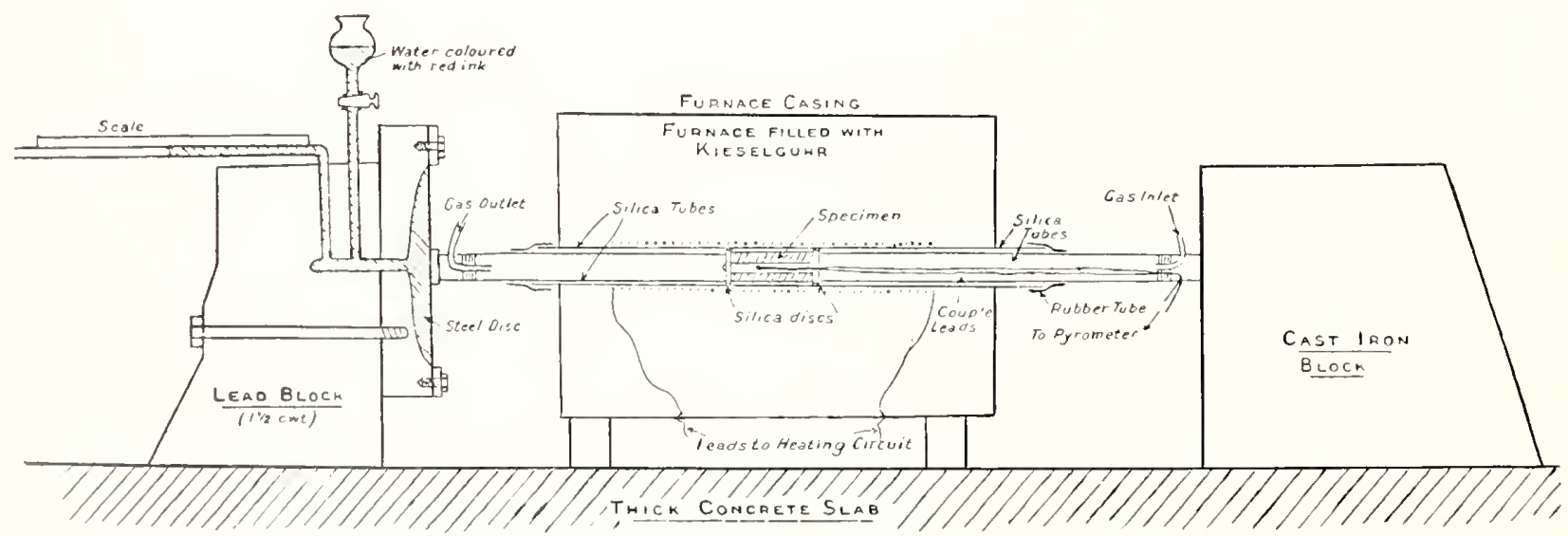

FIGURE 8. Diugrammatic slietch of liquid-micrometer dilatometer (Andrew, Rippon, Miller, and Irragg). 


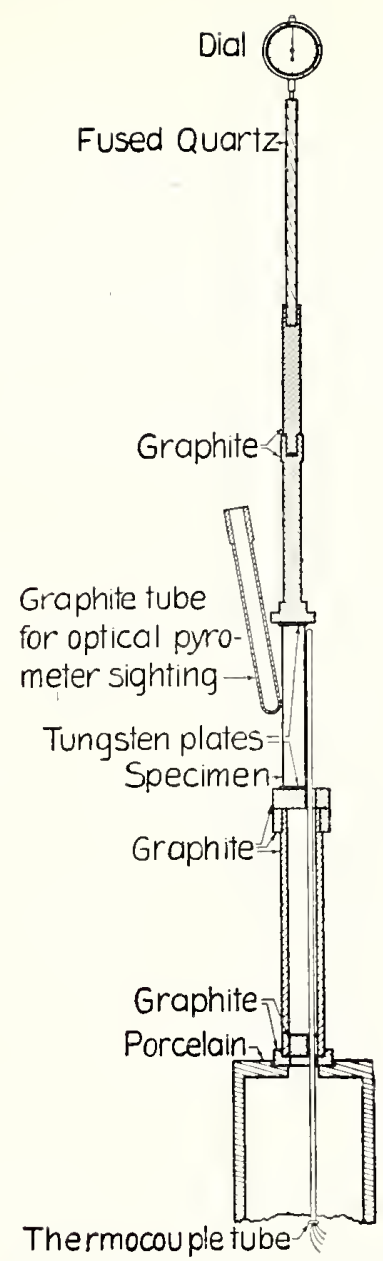

FIGURE 9. Specimen, specimen support, and the system transmitting the expansion in the indurtion furrace (Heindl).

The fused-quartz rod does not extend into the furnace.

'Temperatures were measured with two platinum platinum-rhodium thermocouples up to about $1,500^{\circ} \mathrm{C}$. Then the couples were removed from the apparatus and higher temperatures observed with an optical pyrometer.

From a comparison of dial readings, with this apparatus, on a bar of artificial graphite between $20^{\circ}$ and $1,800^{\circ} \mathrm{C}$ and on a bar of fused quartz of known expansion between $20^{\circ}$ and $1,000^{\circ} \mathrm{C}$, a curve was derived which gives corrections to be applied to the apparent expansion of a sample at various temperatures between $20^{\circ}$ and $1,800^{\circ} \mathrm{C}$. The portion of the correction curve from $1,000^{\circ}$ to $1,800^{\circ} \mathrm{C}$ was extrapolated, since the apparent expansion of artificial graphite showed no irregularities between $1,000^{\circ}$ and $1,800^{\circ} \mathrm{C}$.

\section{Capacitance Method}

A capacitance dilatometer was developed by Prytherch [26] for use in the Metallurgy Department of the National Physical Laboratory. An oscillatory circuit is used and the sample (about 2 an in length) is made to actuate the moving plate of a small capacitor, which constitutes part of the series grid capacitance of the rirruit. Small changes in this eapacitance bring about reatively large changes in the mean steady plate current of the tube. A rontinuous record of the plate current of the tube is made on a recorder, which also simultaneously records the temperature of the sample. The length changes of the sample are eorrelated with temperature. Haughton and Ailcock [27] altered this apparatus somewhat to examine samples at temperatures up to $1,300^{\circ} \mathrm{C}$ in an inert atmosphere. The circent arrangements of the oscillator are those described by Prythereh, but Haughton and Adrock found it artvantageous to screen the oseillator completely by means of a copper-lined box.

\section{X-Ray Method}

With the X-ray method it is possible to determine the cocfficients of expansion of ervstals in different directions over large temperature ranges. A very small amount of material is sufficient for a sample.

When a crystal is heated, the perpendicular distance between its atomic planes parallel to its crystal face gencrally increases. This distance d at any temperature may be determined by an X-ray method from Brage's law [28]

$$
n \lambda=2 d \sin \theta,
$$

where $\lambda$ is the wavelength of a monochromatic beam of X-rays incident upon the clearage face of the crystal, $\theta$ is the angle between the incidrnt X-ray beam and the atomic reflecting plane or the angle between the reflected beam and the same plane, and $n$ is a small integral number that represents the order of reflection. From eq 15, the following equation may be obtained for the average coefficient of linear thermal expansion for a temperature range from $0^{\circ}$ to $t^{\circ}$ :

$$
a_{i}=\frac{\sin \theta_{0}-\sin \theta_{t}}{t \sin \theta_{t}}
$$

where $a_{t}$ is the arerage coefficient of hinear expansion between $0^{\circ}$ and $t^{\circ}$, and $\theta_{0}$ and $\theta_{\ell}$ are the angles indicated previously, at temperatures $0^{\circ}$ and $t^{\circ}$, respectively. From eq 16 it will be noted that it is not necessary to know the value of $\lambda$.

Hull [29] and Delye and Scherrer [30] modified Bragg's method so that a polycrystalline material (thin sheet or powder) ran be used. Some of the crystals in this sample will be oriented so that when monochromatic X-rays are normally incident, they will be reflected from every plane 


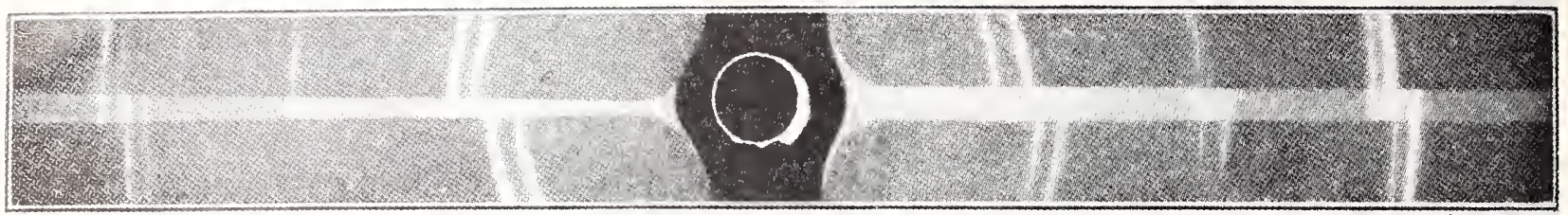

$107^{\circ} \mathrm{C}$

Floves 10. Shifts of the IIull-Delng-Scherer rings of the reflections (11.') and (103) of magnesium, FeK radiation (IIanawalt and Frevel).

sot that is rharacteristiv of the ervetal. A diffraction pattern consisting of conechtrie circles may be ohtained by placing a photographic plate in back of the sample. 'The immermost rircle is caused by those roystals presenting the plano set having the laregest lattere constant at the proper angle for reflection. When the sample is heaterl, the dhange in d will eanse a corresponding reciproeal rhange in $\sin \theta(\sec$ ed 15$)$, and hence in the diameter of the eirele.

If the sample consists of a speck of poweler, it may be supported by a fine wire and rotated so that eomplote lines are obtained on a rylindrial photographic film when the X-rays passing through a slit system are diflracted from the sample. 'The shift in the position of the lines at chiferent temperatures indieates the rhange in the distance d, from which the linear thermal expansion may be computed.

Figure 10 shows the shifts of the Hull-DebyeSehorrer rines of the peffection (114) and (10.5) of magnesium (FeK radiation), obtained by Hanawali and Frevel [31] at $107^{\circ}$ and $207^{\circ} \mathrm{C}$. The sample consisted of a thin disk of magnesium which was mounted in an electric furnace heated by storage bateries. The X-ray beam penetrated an aluminum foil covering that served as a window for the heating chamber. An iron-constantan thermorouple was attehed to the surface of the sample. Two strips of lead covered the quadrants 1 and 3 of the film during the low trmperature exposure, and quadrants 2 and 4 during the high temperature exposure. The films were measured on a comparator and the data used to evaluate the coefficients of expansion of magnesium, parallel to and perpendicular to the $c$-axis.

The X-ray tube used by Shinoda [32] and shown in figure 11, was designed to take Hull-DebyeScherrer photographs with a large angle of reficetion. The body of the X-ray tube made from a brass block 5.5 by 5.5 by $8 \mathrm{~cm}$ is shown in figure 12. A hole, $F, 3.4 \mathrm{~cm}$ in diameter, was bored from one encl of the block to the central part of the flat surface at the other end. The anticathode shown by $b$, and $A$, in figure 12 , was marle from a flat copper or iron block 4.5 by 5.5 by $0.7 \mathrm{~cm}$, having a slightly raised part on one side. This anticathode fits on the flat end of the body of the X-ray tube and the raised part of the antivathode enters hole $F$. As the electrons emitted from the hot eathode are focused on the center of hole $F$, the raised part of the anticathode becomes the sounce of $\mathrm{X}$-rays. I narrow groove extends from hole $F$ and forms a slit for the X-ray beam. I cellophane window covers the slit. The sample, $S$, is placed very close to this window, as shown in figure 12. The distance between the sample and the source of the $\mathrm{X}$-ray beam is about $2.5 \mathrm{~cm}$. The specimen holder is made from a copper block 1 by 1 by $0.5 \mathrm{~cm}$, and the sample, usually a foil, is attarhed on one surface and covcred with layers of cellophane and paper. The other surfaces of the specimen holder are covered with asbrestos. For determinations at $100^{\circ} \mathrm{C}$, steam is introduced through an opening in the specimen holder.
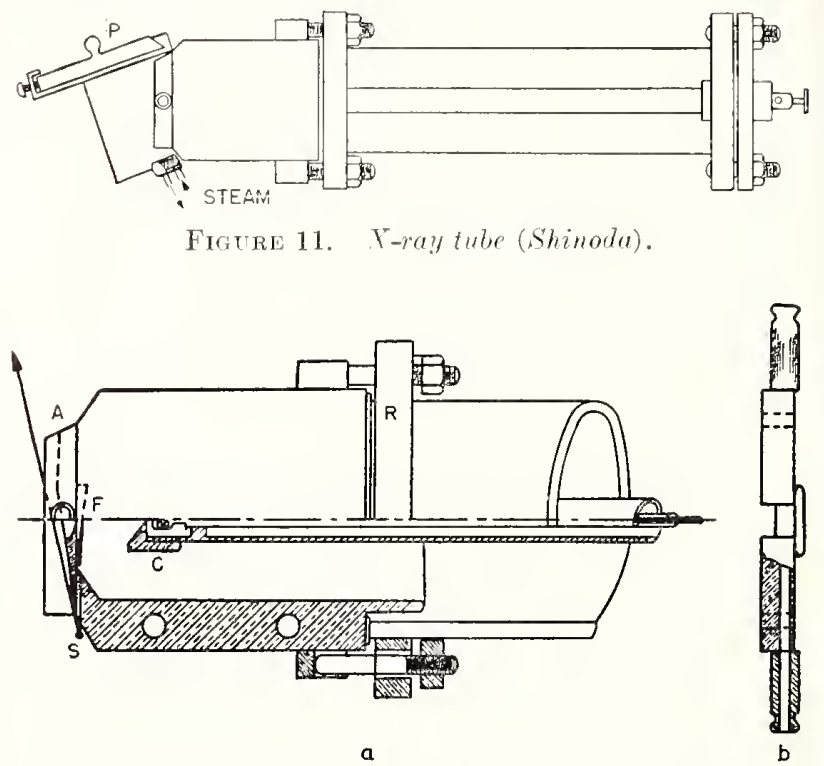

FIGURE 12. Body of X-ray lube $a$, and anticathode $b$ (Shinoda). 
The cathode is an ordinary hot cathode with a ungsten filament covered by a cap, $C$. This cap serves as a focusing device. Its anticathode side $\mathrm{s} V$-shaped to secure a sharp line-focus. Insulation between the cathode and the body of the $\mathrm{X}$ ray tube is attained by a glass tube $17.5 \mathrm{~cm}$ in length and $5 \mathrm{~cm}$ in diameter. This glass tube is connected to the cathode and the body by bolts and nuts through the brass ring $R$, with rubber rings used as packing.

The plate holder $P$ in figure 11 ean move up and down so that four photographs can be taken in succession. With this apparatus, an exposure of 3 to $5 \mathrm{~min}$ is sufficient for each photograph. The X-rays are excited by 5 to 7 ma and $40 \mathrm{kv}$.

Becker [33], Jay [34], and Wilson [35] described $\mathrm{X}$-ray cameras uscd in determinations of the coefficients of linear thermal expansion of materials. The X-ray camera and auxiliary equipment used by Wilson are shown in figure 13 . This camera consists of two circular brass plates, the upper ( $A$ in fig. 13) about 19 'm in liameter', the lower $(B)$ somewhat larger cont aining a groove to receive the cover $C$. The plates are held about $1.1 \mathrm{~cm}$ apart by two brass V-l,locks $D$ and E. Each V-block carries a pair of stainless steel knife-edges that mark out definitely the length of film exposed to the X-rays. "The film, backed by a shect of black paper, is held firmly against the upper plate and the hoss of the lower plate by two strips of steel ribbon on each side. The strips are attached to the back V-block, $D$, and are clipped firmly to the front $V$-block, $E$, by phosphor-bronze springs. The lower diagram of figure 13 shows, on the left sicle of the camera, the film, paper and sted strips lying loosely; on the right side it shows them elipped to the front V-block.

Each plate contains two water-eooling channcls, $F$, and $G$, about $1-\mathrm{cm}^{2}$ section. The water enter's through one of four tubes, $I I$, at the back of the camera, passes through $V$-block $I$, to the upper plate, where it flows half-way round the outer channel until it meets a baflic, through U-tube $J$ to the inner channel, where it flows completely round and through another U-tube to the other half of the outer channel and finally emerges through another of the tubes, $I I$. The circulation in the lower plate is similar.

The furnace consists of two bobbins, $K$ and $L$ (fig. 13), made of oxidation-resistant steel. 'The windings are of platimum insulated from the bobbins by mica. The bolbins are fastened by screws in two soapstone nembers held to the plates of the camera by circular brass clamps $M$ and $N$. The leads from the furnace are taken to small Bakelite terminal hoards on the clamps. The lower clamp, $N$, supports a platinum platinumrhodium thermocouple, $P$. The upper clamp, $M$, contains a ball-race carrying a device, $Q$, for centering the sample. The sample is contained in a thin-walled silica tube that is mounted in a buass rod screwed into a small brass block. This contains two mutually perpendirular grooves into which fit small disks on the ends of two serews. The sample is easily brought into the axis of rotation of the camera by adjusting these serews. 1 third serew clamps the block in position after centering. The sample is turned four times a minute by a small synchronous motor, $R$, that can be swung back oat of the way, when it is necessary to remove the specimen holder. The leads fiom the motor and the upper half of the furnace pass out of the camera through four holes in the frout V-block, E.
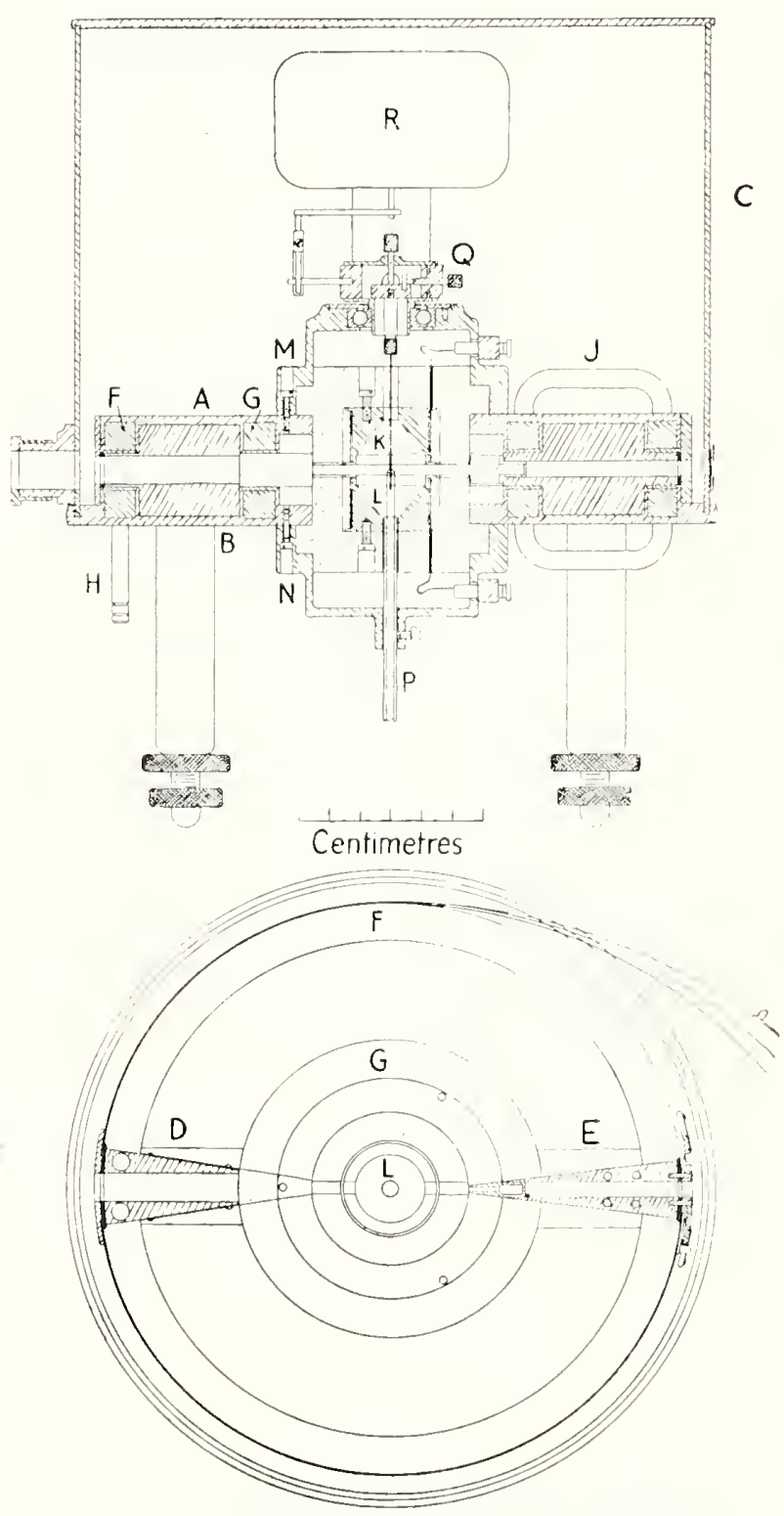

FigUre 13. X-ray camera and auxiliary equipment (Wilson). 
The X-lays antel the eameda (fig. 13) through a small hote in the front of the covere. Filters are placed in a small porket on the outside of the cover whom noeressary. The X-latys pass thromgha a hole in the bleck, $E$, and strike the slit systen, a small removalue brass hoek fitting the inner enel of the hole. The slit itself, about 0.8 hy $3 \mathrm{~mm}$, is at the outer ond of this block; the wider part toward the eentere of the rameral prevents ravs soattered by the ederes of the slit from striking the film. "The rays them pass out of the camedal through a hole in block $D$ lareer than that in block $E$. Two strips fastened to the outside of /l prevent any rays seattered by it from striking the film.

The heating currents in the two furnace bohbins, $K$ and $L$ (fig. 13), an he varied independently. At high temperatures it is neressary to place an opaque sereen betwen the furnace and the film to prevent fogging by the light emitted.

From Bragers law, shinoda [36] derived the following equation for a sample placed at the center of a circular fibm:

$$
\frac{\Delta l}{d}=\frac{1}{2 r}(\cot \theta) \Delta l
$$

where $\Delta d$ is a small variation of $d, r$ is the radius of the film, and $\Delta /$ is the displacement of the line $(/$ is the distane between the lime and the zero position). If a plate perpendicular to the X-ray beam is substituted for a circular film, eq 17 becomes

$$
\frac{\Delta l}{d}=\frac{1}{r} \cot \theta \frac{1}{1+\left(\frac{l}{r}\right)^{2}} \Delta l
$$

The cocfficient of lincar expansion of a cubse crystal may he obtained by dividing $\Delta d / d$ lig the change in temperature. Shimoda gives the following relations for other crystals:

For tetragonal

$$
\frac{\Delta d}{d}=\frac{1}{1+\left(h_{1} c_{1}\right)^{2}}\left[\frac{\Delta a}{a}\left(h_{1} c_{1}\right)^{2}+\frac{\Delta e}{c}\right]
$$

where $c_{1}=\frac{c}{a}, h_{1}^{2}=\frac{h^{2}+k^{2}}{l^{2}}$ and $h, k, l$ are indices of planes.

For rhombic

$$
\stackrel{\Delta d}{d}=\frac{1}{\frac{h^{2}}{a^{2}}+\frac{h^{2}}{b^{2}}+\frac{l^{2}}{c^{2}}}\left[\frac{h^{2} \Delta a}{a^{2}} a+\frac{k^{2} \Delta b}{b^{2} b}+\frac{l^{2} \Delta c}{c^{2}} \frac{\Delta c}{c}\right] .
$$

For licxagonal

$$
\frac{\Delta d}{d}=\frac{1}{1+\left(h_{1} c_{1}\right)^{2}}\left[\frac{\Delta a}{a}\left(h_{1} c_{1}\right)^{2}+\frac{\Delta e}{c}\right]
$$

where $c_{1}=\frac{c}{a}$ and $h_{1}^{2}=\frac{4}{3}\left(\frac{h^{2}+h k^{2}+h^{2}}{l^{2}}\right)$.
From the values of $\Delta d / d$ in the preceding equations, it is possible to calculate $\Delta a / a, \Delta b / b$ and $\Delta c / c$ that correspond to the hinear expancion of the $a-, b-$, and c-axis, respectively. The coefficionts of expansion for these axes may be obtained ly dividing $\Delta a / a, \Delta b / b$, and $\Delta c / c$ by the tomperature change.

Becker [33] determined the coefficients of linear thermal expansion of materials from measurements of the angle $\theta$ at room temperature, and at elevated temperatures up to $2,200^{\circ} \mathrm{C}$. Table 1 gives an example of his data and derived values for silicon. The following equation was used in computing the average coeflicient of expansion:

$$
1+a\left(t_{2}-t_{1}\right)=\frac{\sin \frac{\theta_{1}}{2}}{\sin \frac{\theta_{2}}{2}},
$$

\begin{tabular}{|c|c|c|c|c|c|c|}
\hline \multirow{2}{*}{$(h k 7)$} & \multicolumn{2}{|c|}{$18^{\circ} \mathrm{C}$} & \multicolumn{3}{|c|}{$950^{\circ} \mathrm{C}$} & \multirow{2}{*}{$\begin{array}{c}1+a\left(t_{2}-\right. \\
\left.l_{1}\right)\end{array}$} \\
\hline & $\frac{()_{1}}{2}$ & $\sin \frac{H_{1}}{2}$ & $\frac{\Delta \theta}{2}$ & $\frac{\theta_{2}}{2}$ & $\sin \frac{\theta_{2}}{2}$ & \\
\hline $\begin{array}{l}111 \\
220 \\
311 \\
400 \\
420\end{array}$ & $\begin{array}{ll}21^{\circ} & 30)^{\prime} \\
36 & 40)^{\prime} \\
44 & 25 \\
57 & 40 \\
71 & 1)\end{array}$ & $\begin{array}{r}0.30,55 \\
.5472 \\
.6945 \\
.8450 \\
.9455\end{array}$ & $\begin{array}{r}19 \\
5 \\
9 \\
16 \\
17 \\
31\end{array}$ & $\begin{array}{ll}21 & 25 \\
36 & 31 \\
44 & 15 \\
57 & 23 \\
70 & 29\end{array}$ & $\begin{array}{r}\text { 1. . } 3651 \\
.5951 \\
.6978 \\
.8423 \\
.9425\end{array}$ & $\begin{array}{l}1.0038 \\
1.0035 \\
1.0030 \\
1.0032 \\
1.0032\end{array}$ \\
\hline & & & & & Avg. & 1. 0033 \\
\hline
\end{tabular}

where $a$ is the average coeffieient of linear thermal expansion between temperatures $t_{1}$ and $t_{2}, \theta_{1}$ is the angle at $t_{1}$, and $\Theta_{2}$ is the angle at $t_{2}$.

TABLE 1. Data and derived values for siticon

The average coefficient of linear expansion between $18^{\circ}$ and $950^{\circ} \mathrm{C}$ is

$$
a=\frac{1.0033-1}{950-18}=3.5 \times 10^{-6} \text { per } \operatorname{dog} \mathrm{C} \text {. }
$$

Bccker stated that the accuracy of his detcrminations is 8 pereent for electrically conducting matcrials and 15 pereent for noneonducting materials. Wilson [35] found that the systematic and random errors of his determinations of $d$ are cach about $0.0001 \Lambda$, and that the crrors of the coefficients of expansion are from 1 to 2 percent.

\section{Density Method}

The density method has been used for determinations of the cocfficients of cubical expansion. If the densities of a sample are determined by weighing it in a liquid of known density at two temperatures, $0^{\circ}$ and $t^{\circ}$, the average cocfficient of cubical expansion may be computed from the equation

$$
{ }_{0} \alpha_{t}=\frac{D_{0}-D_{t}}{D_{t} t}
$$


where $\alpha_{t}$ is the average coefficient of cubical expansion between $0^{\circ}$ and $t^{\circ}$, and $D_{0}$ and $D_{t}$ are the densities of the sample at $0^{\circ}$ and $t^{\circ}$, respectively. If the sample is isotropic, the coefficient of linear expansion may be taken equal to onethird the coefficient of cubical expansion.

If the volumes of the sample at $0^{\circ}$ and $t^{\circ}$ are obtained during the density determinations or by another method, the average coefficient of cubieal expansion may be calculated from the equation

$$
{ }_{0} \alpha_{t}=\frac{r_{t}-T_{0}}{\Gamma_{0} t},
$$

where $V_{0}$ and $V_{t}$ are the volumes of the sample at $0^{\circ}$ and $t^{\circ}$, respectively.

The density method has been used previously by Matthiessen [37, 38] and Dewar [39], fol determinations of the coefficients of cubical expansion of various materials. By this method it is possible to make determinations with small ir'egular pieces of materials.

The methods used in determinations of the densities of materials are given in Bureau Circular 487.

\section{Methods for Determinations of Volume Changes in Metals and Alloys During Casting}

The foundryman, in producing a satisfactory casting, has a threefold interest in the shrinkage problem--first, he must make the dimensions of his pattern greater than the dimensions of the desired casting; second, he must employ all possible means to at tain the maximum density in the casting and to produce a metal free from porosity, piping, and gas holes; and third, he must consider the design of his casting in its relation to the tendency of the casting to crack in the mold, as a result of stresses set up by differential shinkage, particularly at sharp angles or abrupt changes in cross section. Determinations of volume changes of metals and alloys during casting are therefore important in design, pattern making, and foundry practice.

When a molten metal or alloy is cooled to room temperature, a change of volume takes place. This change is the algebraic sum of three consecutive volume changes that may be defined as follows:

1. Liquid shrinkage is the volume contraction of a metal or alloy on cooling from any temperature in the liquid state to the freezing point of a metal, or to the begimning of the freezing range of an alloy.

2. Solidification shrinkage (or expansion) is the volume contraction (or expansion) of a metal or alloy on passing from the liquid state at the freezing point to the solid state at the melting point. In the case of a pure metal, the freezing point and the melting point orcur at the same temperature. When an alloy solidifies over a freezing range, the solidifieation shrinkage (or' expansion) is the volume contraction (or expansion) that oceurs fiom the beginning to the end of freezing. 'The soliclification shrinkage of a eutectic or an intermetallic componud, which freezes at a constant temperature, is similar to that of a pure metal.

3. Solid shrinkage is the volume contraction of a metal or alloy on cooling from the melting point in the solicl state to any lower temperature, usually room temperature.

Liquid shrinkage is a definite physical property of a metal or alloy. Soliclification shrinkage is essintially a constant for a pure metal, entectic, or intermetallic compound. However, in alloys of the solid-solution type, the solidification shrinkage is complicated due to the fact that the soliel that separates from the melt during freezing continually changes in composition. During this selective crystallization stresses may be set up on account of diflerent coefficients of expansion. Solid shrinkage of a metal or alloy may also be variable. Stresses may exist in a east alloy of the solid-solution type as a result of progressive solidification and structural transformations after solidification. Such stresses may also be due partly to temperature gradients set up during cooling.

As a result of these stresses in a cast alloy, the observed linear contraction of a bar, designated as patternmaker's shrinkage, may differ from that calculated from available data on linear thermal expansion of the alloy. Another factor which influences the difference between the linear thermal expansion of a metal or alloy and the patternmaker's shrinkage, is the apparent failure of a casting to register the true shrinkage taking place at and slightly below the melting point. The cause of this may possibly be due to the fact that material at the grain boundaries loes not possess sufficient rigidity to register the actual contraction of the grains or crystallites.

The contraction of liquid metal as it cools and solidifies is distributed between external pipe and internal voids. Except where conditions are such that a completely rigid shell is formed about at cooling mass of inolten metal before the interior has reached the freezing temperature, the shrinkage caused by contraction of the liquid interior will result in a depression in the upper surface (external pipe). Shrinkage that takes place during the change of state may contribute largely to the production of internal voids, when such tendency is exhibited by the metal or alioy.

The distribution of the shrinkage, or contraction, during solidification, in the form of an external pipe, internal pipe, or small cavitics (porosity) throughout the casting, will depend largely on the following factors: (a) The magnitucte of the shrinkage during solidification, (b) the freezing temperature of the metal, (c) type of metal, 
whether it is pure, cutcotic, intrometallic rompound, solid solution, or any combination of these, (d) Huidity of the motal, (o) themal romductivity heat capartity, and pouring temperature of the metal, (f) horation and design of gates and risers, (g) ratio of sudiace atrea to volume, and (h) hade capacity, thermal romelustivity, and initial temperature of the mold material.

In 1932 Siloger and Ash [fo] described a method for determinme the volume changes acemping when a molten motal is rooled to room tempratature. Ther ohtained data from which specifie

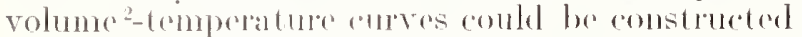
for the range from the molten state to room temperature.

In figure 14, $T_{a}-T_{b}$ represents the rhanger in specifie volume with change in temperature of a metal in the liquid state as it cools fiom some temperature, a, to the freezing temperature, b. The interval $r_{b}-r_{c}$ represents the change in sperific volume of a metal in passing from the liquiel state at temperature $b$, fo lhe soliel state at temperature $e^{2}$ The intorval $V_{c}-V_{d}$ represents the change in sperefife volume of the soliel motal as it rools from the melting point a, to room trmperature, d. Thlor changere in volume, in pereent, for any interval ran be calculated from the dillorence in sperifie volumm for the interval; thus $100\left(\mathrm{~T}_{a}-\right.$ $\left.T_{b}\right) / V_{a}$ reperesents this whange on rooling the metal from temperature a to temperatture b.

\section{(a) Liquid Shrinkage:}

Saceger and dsh f40] devised an apparatus for detemining the sperific rolumes of molen metals and alloys orer a wile range of temperatures. The appanatus is shown in figures 15 and 16. It is essentially a pichomoter, lut is designated a "crucible immersion apparatus." The crueible, lid, and supporting rods were made of Acheson graphite.

Graphite is matisfaretory for the sampline of rast iron berause of the reaction betweren the iron and the graphite, which changes not only the dimensions of the revible but also the composition of the imon. It was fomel, howerere, that graphite cam be profereded from the action of molten cast inon ly surfacing it with a refractory "wash." Zireonium-oxide powder to which had been added a small amount of colloidal alay for bond and mixed with water to a "consistency" of eream" was fomml to be satisfactory.

The tomperature of the molten metal is measured by mons of a platioum platinum-rholium thermocouple within a glazerl-poredain protection tube placed inside a graphite tube 1 in. in diameter. The graphite tube is treated with the refractory roating described previously, when it is to be immersed in cast iron.

2 Sprecife volume is the reciprocal of the density, or the rolume in milliliters pier gram.

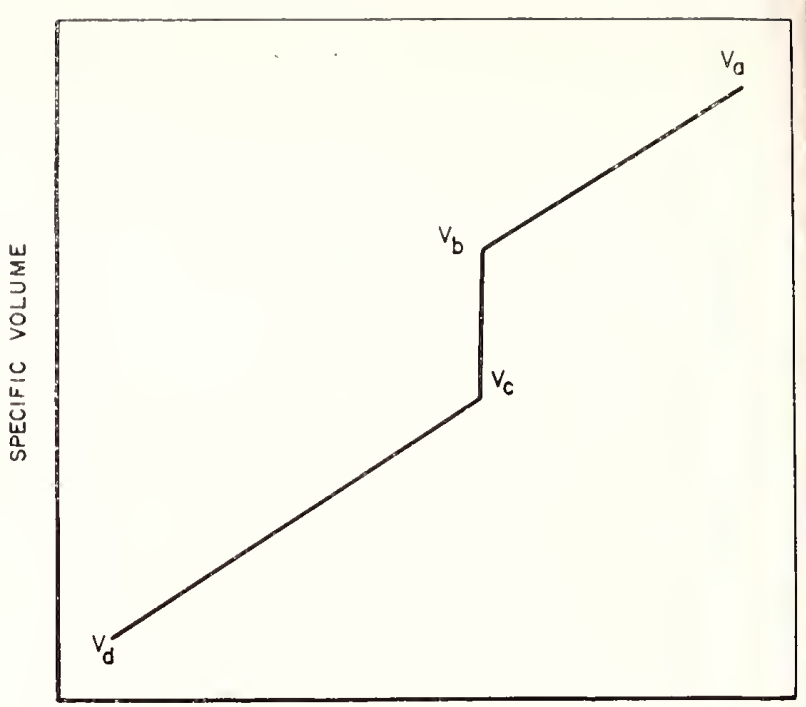

TEMPERATURE

Fingre 14. Typical specifit volume-temperature curve of a metal (siafger and Ash).

\section{(b) Solidification Range}

For alloys that solidify over a freczing range, it is necessary to letermine the freezing point (the temperature at which incipient crystals form on cooling) and the molting point (the temperature at which imeipient fusion bregins on heating). These temperatures may be determined by a thermalmalysis method. The interval between the freczing point and the melting point is the solielification lange.

With this apparatus it is possible to isolate a known volume of liquid motal at a definite and predetermined temperature from a ladle of molten metal. The procedure is as follows: The cencible is filled by immersing it in a ladle of molten metal and sulficiont time is allowed for the rerucible to come to the temperature of the surrounding metal, ol to allow both crueible and metal to cool to the temperature at which it is clesired to obtain a sample. When the desired temperature is reached the lid is pressed down firmly on the crucible, and the whole assembly removed from the ladle of motal.

The sample of metal thus obtained is allowed to freeze within the arucible and to cool to room temperature. Obviously the mass of the metal loes not change on cooling. The resulting ingot is weighed at room temperature. The specific volume of the metal at the temperature of sampling is ealculated by dividing the volume of the crucible at that temperature by the weight of the ingot.

The volume of the crucible at room temperature was determined by wrighing the mercury required to fill it, when the hil was pressed down firmly. The volumes of the graphite crucible at clevated temperatures were calculated from data on linear thermal expansion of graphite.

Cireulars of the National Bureau of Standards 
Saeger and Ash [40] used cast samples 5 in. long and $1 \frac{1}{2} \mathrm{in}$. in diameter to determine the solidifieation range. A $3 / 8-i n$. hole, $4 \mathrm{in}$. long, was drilled along the longitudinal axis of the cylindrical sample into which was inserted a platinum platimum-rhodium thrmocouple protected by means of a glazed-porerlain tube. The sample was mounted in a 4 -in. coil of a high-frequency induction furnace and the intervening space filled with zircon sand. The electromotive force developed by the thermocouple was measured by means of a potentiometer. 'The time in seconds required for' each successive change of $0.1 \mathrm{mv}$ was recorded, and inverse-rate heating and cooling curves of the sample were obtained. The freezing point was taken as that temperature at which the first break occurred in the cooling curve, and the melting point as the first break in the heating curve.

\section{(c) Solid Shrinkage}

In addition to determining the specific volumetemperature curve for the liquid metal, it is neces- sary to determine a similar curve for the metal on cooling in the solid state. Thermal-expansion data for many metals are a vailable in the literature, and ean be used for ealeulating the specific volumeiemperature relations for solid metals. In the case of gray east iron, however, thermal-expansion data obtained by heating a gray-iron casting will not answer the purpose because heating causes permanent growth as indieated in figure 17 . It is necessary, therefore, to obtain data on the contraction of gray cast iron as it cools from the melt.

The dimensional changes occurring during the cooling of cast iron are affected by the separation of graphite. On freezing and during cooling, the cementite undergoes a partial transformation to ferrite and graphite. As the specific volume of graphite is about three times that of cementite, the transformation results in an increase in volume. This increase varies with the amount of cementite decomposed and therefore is dependent on the composition of the cast iron, particularly the carbon, silicon, and manganese contents, and on the rate of cooling. The dimensional changes

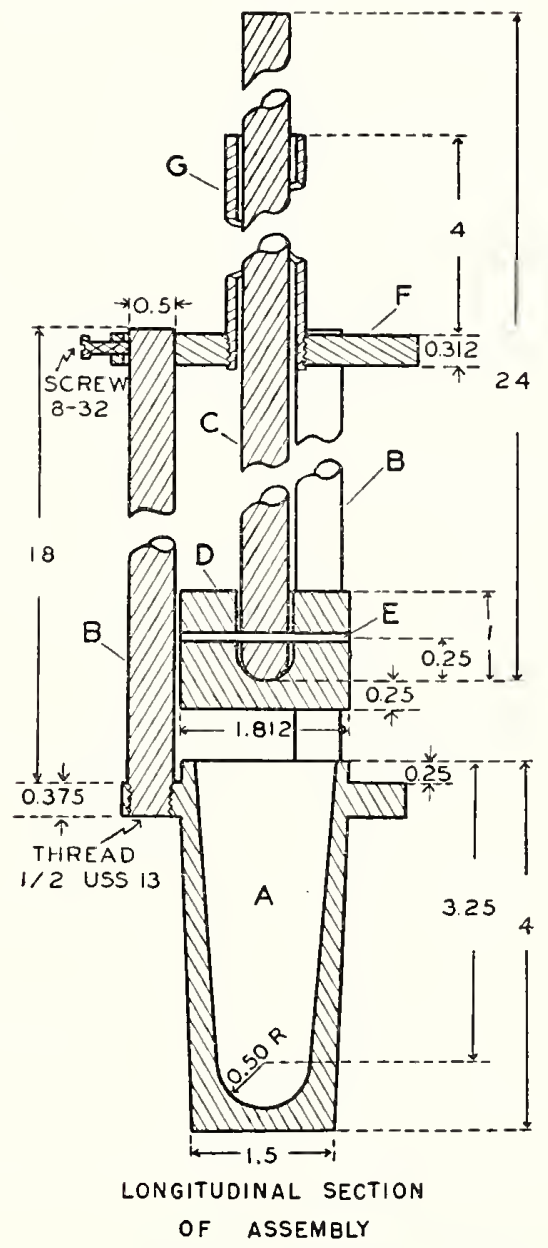

DIMENSIONS IN INCHES
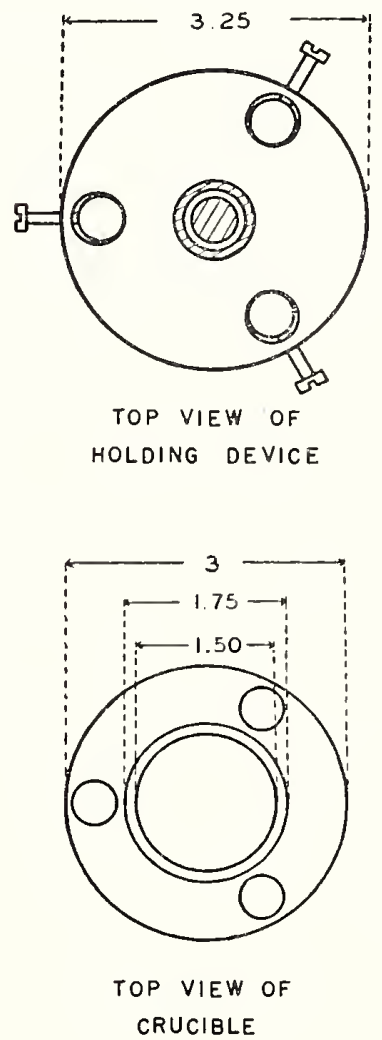

FIGURE 15. Crucible immersion apparatus (Saeger and ish).

$A$, Crucible; $B$, support rods; $C$, control rod; $D$, lid; $E$, sustaining pin (4-min carbon are rod); $F$, met $x$ base; $G$, metal handle. 


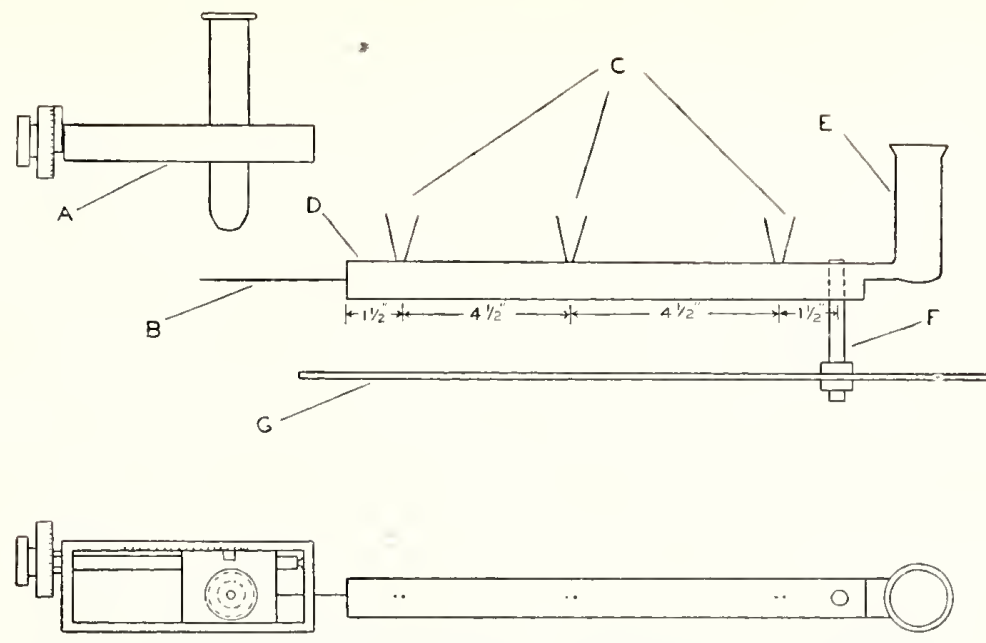

FIGURE 1S. Skctch of apparatus for determining linear contraction of metals amd alloys (Sacger amd ish).

1. Mierometer slide and microscope; $B$, fused-quartz rod; $C$, thermocouples; $D$, shrinkage bar; $E$, pouring gate; $F$, fixed stenl pin; $G$, steel plate.

reading of the instrument. Chromel-alumel thermocouples and a portable potentiometer indicator were used to indieate temperatures. The wires of the thermocouples were insulated from each other and from the molten metal by means of a sodium silicate silica-flour cement. The welded tip of each thermocouple extended into the mold cavity to one-half the thickness of the resulting bar.

The procechure was as follows: A shrinkage bar was cast by pouring molten metal from a ladle into a green-sand mold. The temperatures of the cast bar were read simultaneously with observations on the movement of the fused-quartz rod. The contraction curve was obtained from those data.

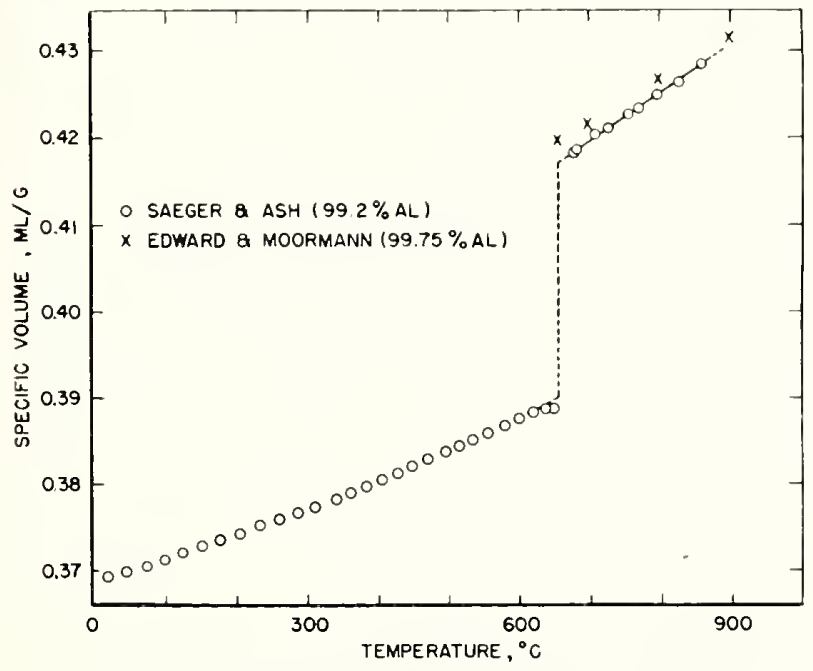

FIGURE 19. Specific volume-temperature curve for aluminum (Saeger and Ash).

Solidification shrinkage 6.6 percent; solid shrinkage $\left(658^{\circ}\right.$ to $25^{\circ}$ C) 5.5 percent.

\section{(d) Specific Volume-Temperature Curves}

Saeger and $A$ sh [40] determined the specific volume-temperature curves for some nonferrous metals and cast irons. The procedure used in obtaining the specific rolume-temperature curve for aluminum will be briefly indicated as an eximple.

The specifie volume of liquid aluminum at $770^{\circ} \mathrm{C}$ was calculated as follows from experimental data obtained with the erueible immorsion apparatus:

Specific volume of aluminum at $770^{\circ} \mathrm{C}$

Volume of liquid aluminum sample at $770^{\circ} \mathrm{C}$

$=$ Weight of liquid aluminum sample at $770^{\circ} \mathrm{C}$

Tolume of graphite crucible at $770^{\circ} \mathrm{C}$

Weight of aluminum ingot at $100 \mathrm{~m}$ temperature

$$
=\frac{68.18}{160.99}=0.4235 \mathrm{ml} / \mathrm{g} \text {. }
$$

In a similar manner, the specific volume of liquid aluminum was determined at other sampling temperatures. By plotting these values, the upper portion of the eurve in figure 19 was obtained. This portion of the curve represents the specific volume of liquid aluminum at various temperatures.

Measurements of changes of length with temperature were made on a 1-in. square bar of aluminum of 99.2 percent purity during the period of cooling from its melting point $\left(658^{\circ} \mathrm{C}\right)$ to room temperature. As may be observed from the lower portion of the curve in figure 19, the 
solid specific volume-temperature curve tends to fatten out just holow the melting point, as the east bar may not have beren sufficiontly rigid at this high temperature to logister the true rontrartion taking place. This condition was overeome by catrapolating the main portion of the colre to the molting point. The observed linear antraction of the bar (12 in. long at the asting tentperature) from the medting point to room temperature wats 0.213 in. (1.78 pereont) and as (o)rreoted for the extrapolated portion, 0.222 in., or 1.85 pereent

The cubical contraction was taken as three times the lineal contraction. The value 5.55 pereent (3) 1.85 pereent represents the derensese in volunne undereone by aluminum in rooling from the melting point to room temperature, and agrees closcely with the value 5.57 pereent for the cubieal enotraction of ahminum of the same purity calculatod, by extrapolation from lincal thermat-repansion dita given by Hidnert [11].

'The sperifie volume of a sample rut from this (ast har of aluminum, after foreging at $4000^{\circ}$ ('and annoaline at $450^{\circ} \mathrm{C}$, was determinced as 0.368 .3 $\mathrm{ml} / \mathrm{g}$ at $20^{\circ} \mathrm{C}$. The corresponding sperifie volume of aluminum in the solid state at $6.58^{\circ} \mathrm{C}$ is 0.3899 )

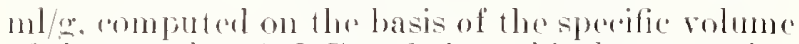
of the motal at $20^{\circ} \mathrm{C}$ and the cubiral contration of 5.55 pererent on rooling from $6.55^{\circ}$ to $20^{\circ} \mathrm{C}$.

By extrapolating that portion of the anve (fig. 19) reperesenting the speritie volume of liguid aluminum, to the freoring point $\left(655^{\circ}\right.$ ( C), the specitie volume of hquil alumimum at the freeging point was folmel to be $0.4173 \mathrm{ml} / \mathrm{g}$. Tlu. diflerenee hetween the sperifie rolumes of liquid and solid ahmoninum at $6.5 S^{\circ} C^{\circ}$, the rhange in the specilie volume ransed hy solidifieation shrinkage, is ayulal to $0.4173-0.3899=0.0274 \mathrm{ml} / \mathrm{M}$. This is rquiralent to 6.6 pereent, based on the specific volume of the liequid at the fierring point.
The specifie volume-temperature curve of aluminum from about $900^{\circ}$ C to room temperature is shown in figure 19. Several values reported by Edwards and Moormam [42] were also plotted in this figure for comparison.

The lincar contraction of commeredal alluminum in the solid state, reported by Anderson [4:3] is apprecoiably less than the value ealeulated from lata on linear thernat expansion. He found that his results for the lincar contraction of aluminum and many of its alloys varied as follows: other comditions being equal, (a) the smaller the cross section of a rast har of given length, the less the contraction, (b) the greater the length for a given coss section, the less the contraction, and (c) the rontraction was loes in rhill molds than in salmel-cast molds.

\section{(e) Other Methods}

Coloman [44] fomm a lincar casting shrinkage of 1.25 pereent for a gold-copper alloy containing 10 pereent of ropper, whereas the linear contraction of the solid alloy from the melting point to $20^{\circ} \mathrm{C}$, computed from thermal expansion data, was 1.62 perecent. The appariatus used for measming the linear casting shrinkage is shown in figure 20. The procerlure was as follows: The ladere caps were solewed tightly into the ends of the flask, and the small hollow plugs serewed into the caps and locked in position with lock nuts. A motal rod, inserted through and supported by the hollow plugs, served as the pattern. The sprue was attached to the pattern with wax, the crucible former placed in position and the llask filled with dental investment. After the investment had set, the crueible former, sprue, and pattern rod were removed. The hollow plugs were replaced with the solid plugs, thus forming a mold, the length of which is determined solely by the distanes botween the inside

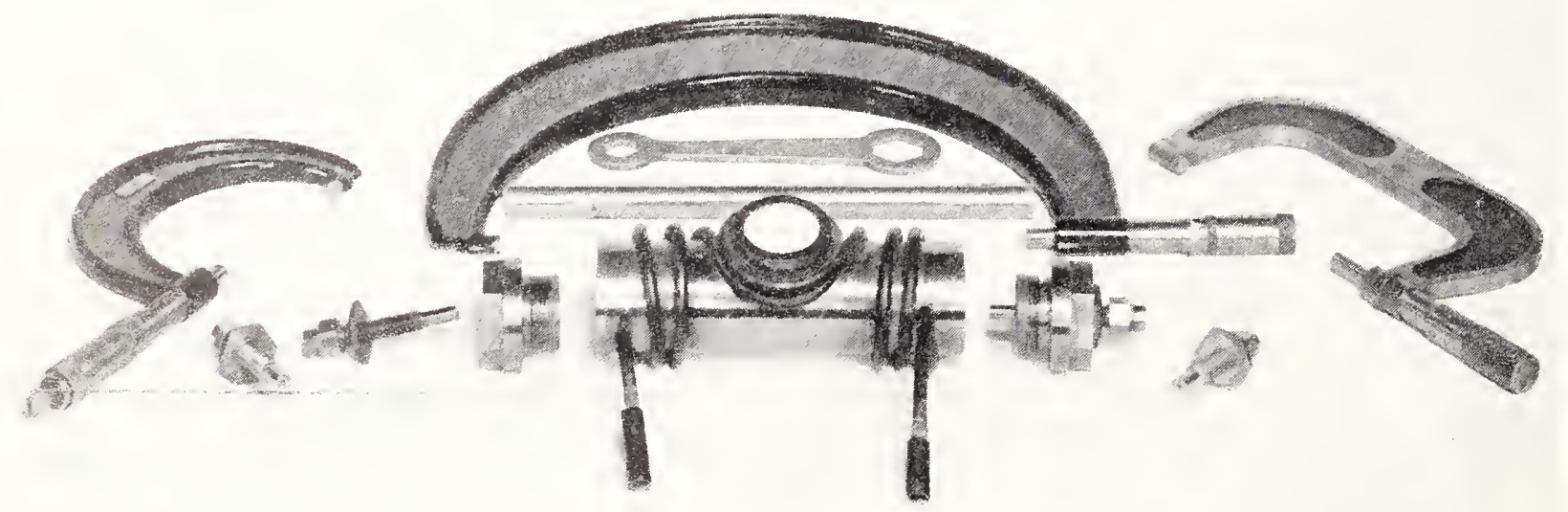

FrGURE 20. Apparatus for determining the linear casting shrinkage of gold alloys (Coleman). 
- faces of the solid plugs. The flask was then placed in an oven and "burned out" at the clesired temperature. Castings approximately $3 \frac{1}{4}-\mathrm{in}$. long and $0.12 \mathrm{in}$. in diameter, were made with an air-pressure machine.

The metal parts of the apparatus are of an oxidation-resisting steel, the coefficient of linear thermal expansion of which is known. The temperatures of various parts of the flask were measured with small thermocouples and a potentiometer. The length, at room temperature, of each of the solid plugs was determined accurately. The distance between the outside faces of the solid phugs was measured with a micrometer. From these values the distance between the inside faces of the solid plugs, or the length of the mold, was computed.

Two possible explanations of the difference between the observed linear casting shrinkage of the gold alloy, and the calculated linear contraction from thermal-expansion data were suggested by Coleman [44]: (1) 'There may be sufficient friction or interlocking between the casting and the walls of the mold to hold and stretch the easting while it is cooling through that range of temperature within which the metal is very soft or weak, thus preventing the full normal shrinkage, and (2) the compensation of part of the total slurinkage of the solid metal may be dependent upon a difference in the rates of cooling of different parts of the casting. If part of the metal in the mold solidifies and cools to some temperature below the melting point before the metal in the sprue freezes, the shrinkage caused by the cooling of this solid metal may be compensated by the addition of metal from the crucible.

Other methods that have been employed for measuring the volume changes undergone by a metal in cooling from the liquid state to room temperature have been reviewed by saeger and Ash [40] under four headings - dilatometric; buoyancy; picnometer; sand-cast sphere, cone, or cylinder.

\section{Data on Thermal Expansion}

From observations on the linear thermal expansion of a sample of material it is possible to derive an empirical equation showing the relation between linear expansion and temperature. For example, the following second-degree equation was derived for molybdenum (fig. 21) by the method of least squares:

$\Delta L=4.090(t+142.5) 10^{-6}+0.00226(t+142.5)^{2} 10^{-6}$,

where $\Delta L$ represents the change per unit length from the length at the initial temperature $-142.5^{\circ}$ $\mathrm{C}$, and $t$ represents any temperature between $-142.5^{\circ}$ and $+305^{\circ} \mathrm{C}$. The probable error per unit length of molybdenum was found to be $\pm 8.3 \times 10^{-6}$. This value may be affected by the departure of the expansion curve from the assumed parabolic law.

The first derivative of eq 25 gives

$$
\frac{d}{d t}[\Delta L]=4.090 \times 10^{-6}+0.00452(t+142.5) 10^{-6}
$$

and represents the tangent or instantancous coefficient of expansion $a_{t}$, at any temperature $t$, between $-142.5^{\circ}$ and $+305^{\circ} \mathrm{C}$.

$\mathrm{Eq} 25$ can be transformed into the following form:

$$
L_{t}=L_{0}\left[1+\left(4.73 t+0.00226 t^{2}\right) 10^{-6}\right]
$$

where $L_{t}$ is the length of the sample at any temperature $t$, between $-142.5^{\circ}$ and $+305^{\circ} \mathrm{C}$, and $L_{0}$ the length at $0^{\circ} \mathrm{C}$. In this equation, $4.73 \times 10^{-6}$

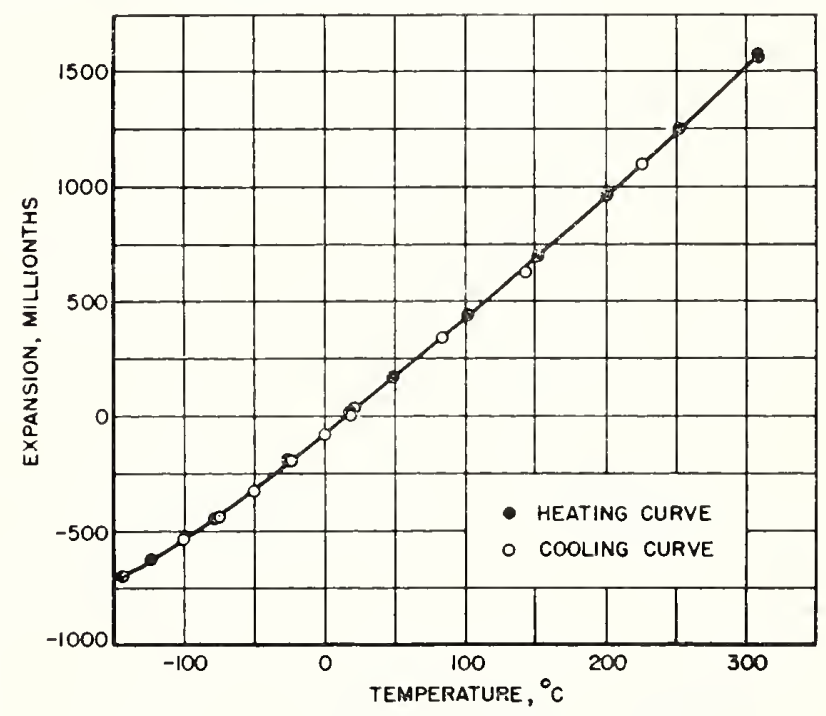

Figure 21. Linear thermal expansion of molybdenum.

represents the instantaneous coefficient of expansion at $0^{\circ} \mathrm{C}$.

From observations with the initial temperature at any temperature (usually room temperature), Souder [45] in 1918 derived two normal equations from which it is possible to compute directly two constants of a second-degree cyuation in terms of $L_{0}$, the length of a sample at $0^{\circ} \mathrm{C}$. These normal equations are

$$
\begin{aligned}
& a \Sigma(\Delta t)^{2}+b \Sigma \Delta t^{2} \Delta t=\Sigma \bullet \Delta t \\
& a \Sigma \Delta t^{2} \Delta t+b \mathbf{\Sigma}\left(\Delta t^{2}\right)^{2}=\mathbf{\Sigma} \in \Delta t^{2},
\end{aligned}
$$


whare a and $b$ are constants, $\Delta t=t_{n}-t_{1}$, or the change in observed temperatere from the initial temperature $t_{1}, \Delta t^{2}=t^{2}{ }_{n}-t^{2}{ }_{1}$, or the change in the square of the observed temperature from the square of the initial temperature $t_{1}$, and $e$ is the correspondine olusered linear expansion per unit length from the intial temperature.

The constants a amel $b$ may be obtained by solving these normal aquations by determinants. This methorl gives

and

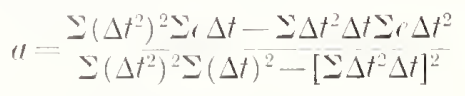

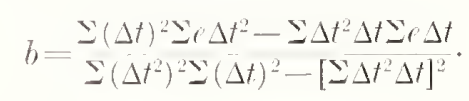

The values computed for $a$ and $b$ may then be substituted in eq 3 .

Coeflicients of expansion of various materials are given in the following publications:

International Critieal Tables.

Landolt-Bomstein Physikalisol-Chemische Tabollen.

Smithonian Physira! 'Tables.

National Burrau of Standarels Circular C447, Mechanieal Properties of Metals and Alloys.

Tambooks.

A chart indieating the linear thermal expansion of 18 materials on heating from $0^{\circ}$ to $100^{\circ} \mathrm{C}$ is shown in figure 22.

\section{Relations between Thermal Expansion and Other Properties}

From the data obtained on a sample by means of one of the dilatometrie methods, it is possible to plot a eneve which shows the relationship between

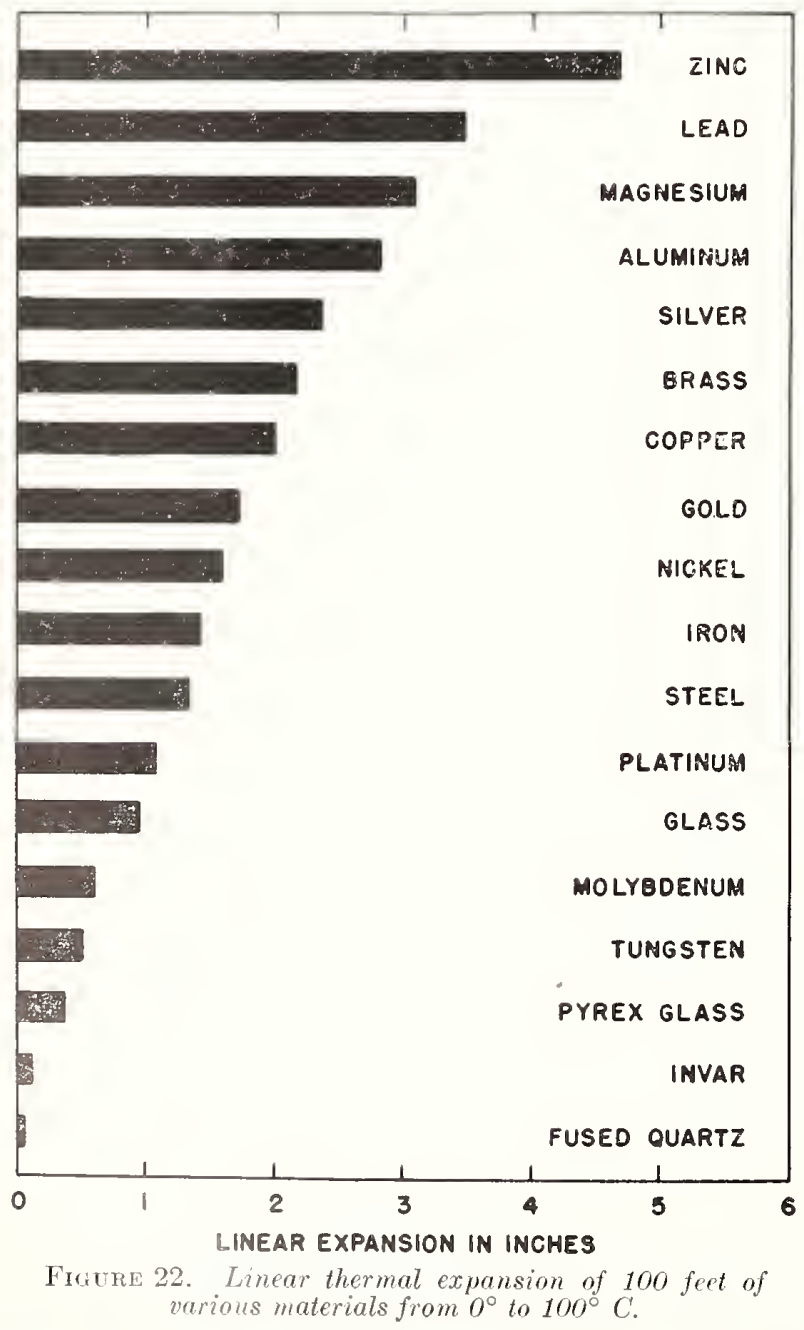

expansion and temperature, on heating and cooling. The curve on cooling may or may not coincide with the curve on heating, depending on the nature and the previous treatment of the sample. Fom the rxpansion curve it is possible to compute average coefficients of expansion for various temperature langes, or an empirical equation may be derived from the original data.

Dilatometre methods permit the investigation of slow or lappid reactions, and a quantitative description of transformations. These changes observed during the heating and cooling of a sample are caused by transformations of the constituents (allotropic phase transformations, anomalous transformations without change of phase, and decomposition of phases) and by the reactions between phases. Iron is an example of a metal which undergoes a transformation with change of phase. When alpha iron (body-centered cubic crystal structure) is heated, it undergoes an allotropic transformation $\alpha \rightarrow \gamma$ at about $910^{\circ} \mathrm{C}$, with a contraction for several degrees higher. On being further heated above this temperature $\left(A_{3}\right)_{3}$, gamma iron (face-centered cubic erystal structure) expands. On rooling, gamma iron undergoes an allotropic transformation $\gamma \rightarrow \alpha$ at about $900^{\circ} \mathrm{C}$ with an expansion. On further cooling below this temperature $\left(A r_{3}\right)$, alpha iron contracts.

Figure 23 shows the linear expansion of a carbon steel on heating and cooling between $20^{\circ}$ and $900^{\circ}$ C. This steel expanded regularly to $729^{\circ} \mathrm{C}$ $\left(A c_{1}\right)$ and then contracted to $759^{\circ} \mathrm{C}\left(A c_{3}\right)$. During this range from $729^{\circ}$ to $759^{\circ} \mathrm{C}$, alpha iron transformed to gamma iron, and iron carbide went into solution in gamma iron. At $759^{\circ} \mathrm{C}$, the steel resumed its expansion at higher temperatures. On cooling, the steel contracted regularly to $685^{\circ} \mathrm{C}\left(\mathrm{Ar} \mathrm{r}_{3}\right)$, when expansion started with a transformation to alpha iron. The expansion continued on cooling to $659^{\circ} \mathrm{C}\left(A r_{1}\right)$. On further 
cooling to $20^{\circ} \mathrm{C}$, the steel contracted in a normal manner.

Dilatometric data may be used not only for obtaining relationships between thermal expansion and temperature, and for investigations of the constitution of metals and alloys, of dimensional changes on hardening steels, aging phenomena of alloys and steels, kincties of transformations of austenite during cooling of steels and thring isothermal holding below the eutectoid temperature, and of graphitization of cast iron; but also for obtaining relationships between thermal expansion, chemical composition, thermal and meehanieal treatments of materials, and the like. For example, the following equation shows the relationship between linear thermal expansion and chemical composition of cold-rolled copper-zinc alloys:

$a_{50}=\left(22.923-0.06833 \mathrm{X}+0.0000695 \mathrm{X}^{2}\right) 10^{-6}$

where $a_{50}$ is the instantaneous coefficient of expansion at $50^{\circ} \mathrm{C}$, and $X$ is the copper content between 62 and 97 pereent by weight.

Grüneisen's law [46], first dedueed empirically in 1908, states that for a metal the ratio of the coefficient of linear expansion to its specific heat at constant pressure is constant at all temperatures. Various theories of the solid state lad to the relation

$$
3 a=d b k c,
$$

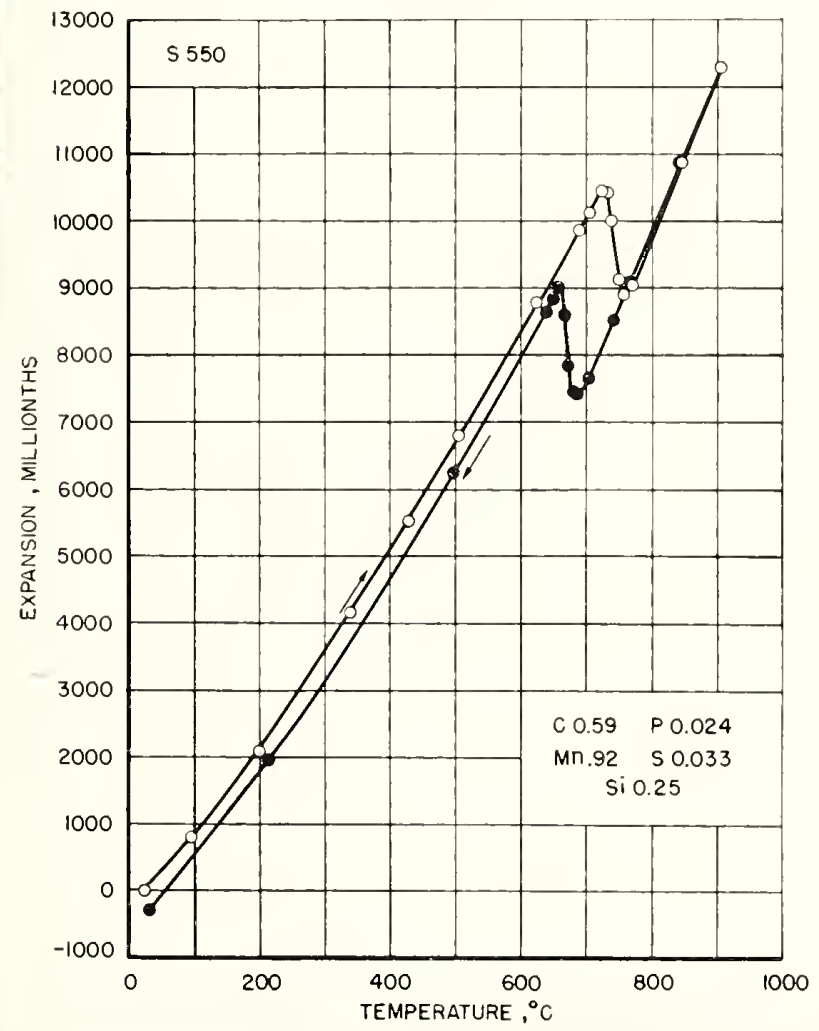

Figure 23. Linear thermal expansion and transformations of steel. where $a$ is the coefficient of linear expansion, $d$ is the density, $b$ is the compressibility, $k$ is approximately a constant, and $c_{n}$ is the heat capacity at constant volume. Wilson [35] showed that this relation may be derived by a mothod which is thermodynamieal, exeept for the assumption of the Deliye or some similar expression for $c_{V}$. Neither Grüncisen's law or eq 33 is well obeyed at high temperatures.

Hume-Rothery [47] adopted the following modification of Grüncisen's relation used by Simon and Volsen [48]:

where

$$
\frac{V_{T}-V_{0}}{V_{0}}=\frac{E_{T}}{Q_{0}-l E_{T}},
$$

$T_{0}=$ volume at absolute zero

$V_{T}=$ volume at $T^{\circ} \mathrm{K}$

$E_{T}=\int_{0}^{T} c_{n} d T$

$Q_{0}=\frac{c_{p}}{3 a}+2 k E_{T}$ (where $c_{p}$ and $a$ are the

values of the specific heat and coefficient of expansion at room temperature)

$$
k=\text { constant }=\gamma+\frac{2}{3}
$$

where

$$
\gamma=\frac{-V \frac{\partial V}{\partial T}}{c_{v} \frac{\partial V}{\partial p}}
$$

Hume-Rothery stated that for most metals $Q_{0}$ is of the order $10^{4}$ to $10^{5} \mathrm{cal}, k$ is a small number of the order 1 to 3 , and $E_{T}$ is of the order 1,000 at room temperature and increases hy about 600 for each 100 deg rise of temperature. He found very good agrement between the observed and calculated changes in volume of the culie metals silver, copper, and aluminum between absolute zero and a temperature of the order two-thirds of the melting point on the absolute scale, but for iron he found good agreement only up to the temperature at which the magnetie transformation begins.

Carnelley [49] and lémeray [50] showed an approximate relation between the coefficients of linear expansion and the melting points of the chemical elements. Avaibule coefficients of linear thermal expansion of the chemical clements at room temperature or for the range from $20^{\circ}$ to $100^{\circ} \mathrm{C}$ versus their melting points $\left({ }^{\circ} \mathrm{K}\right.$ ) are plotted in figure 24. The hyperbolic curve was derived from data on body-centered cubic and face-centered cubic dements, except manganese and the alkali metals. The curve indicat es that the cocffi- 


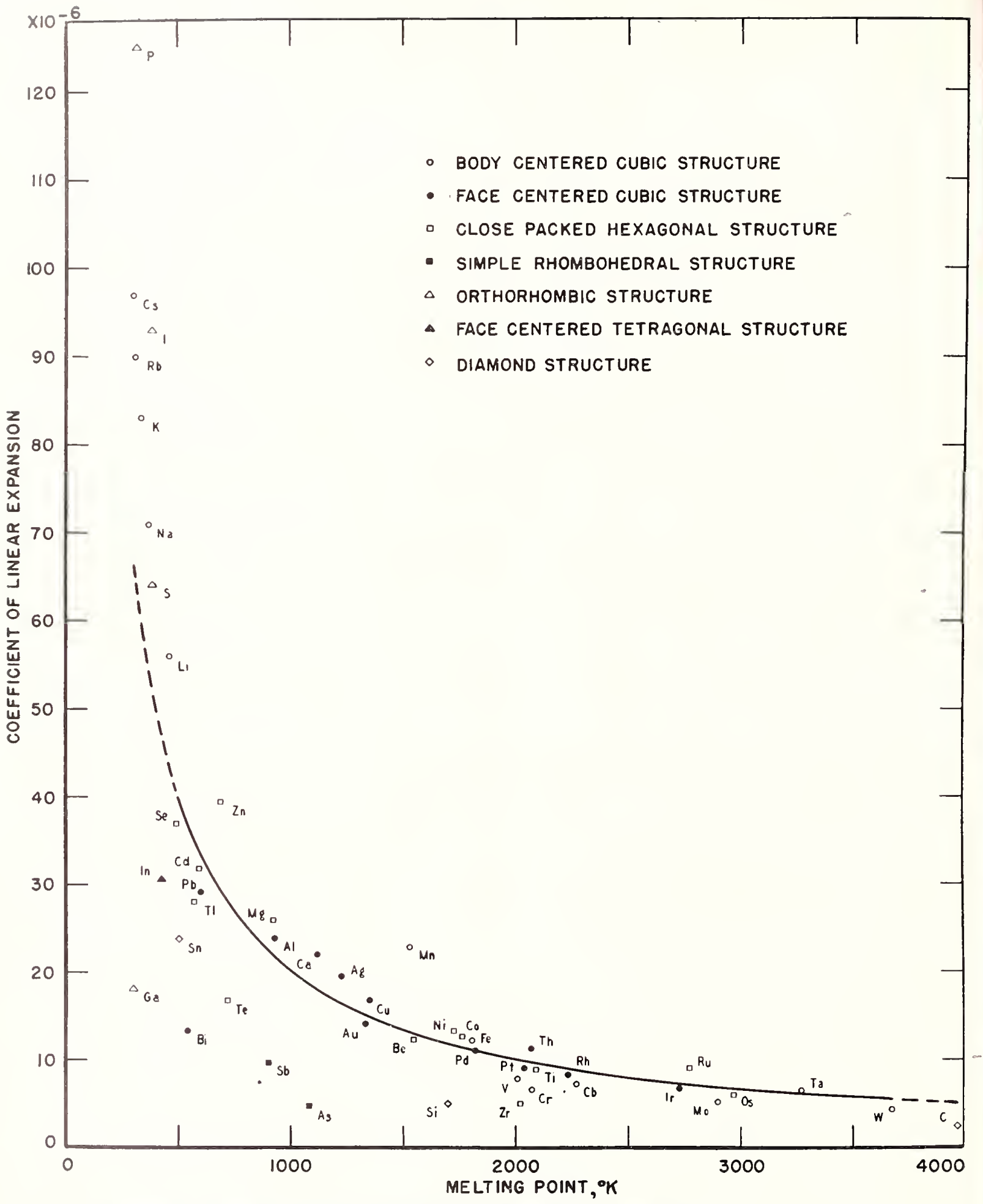

FIGURE 24. Relation between coefficients of linear thermal expansion (at room temperature or for the range from $20^{\circ}$ to $100^{\circ} \mathrm{C}$ ) and melting points of chemieal elements.

Curve derived from data on body-centered cubie and face-centered cubic elements, except manganese and the alkali metals. 
cients of linear expansion of the elements decrease as their melting points increase. The coefficients of expansion of the low-melting elements are relatively very large compared to those of the high-melting elements. Most of the elements having body-centered cubic, face-centered cubic or close-packed hexagonal structures lie close to the curve. The elements In, Sn, Ga, Bi, Te, $\mathrm{Sb}, \mathrm{As}$, and $\mathrm{Si}$ lie appreciably below the curve. Most of the elements that do not lie close to the curve have melting points below $1,000^{\circ} \mathrm{K}$. The curve may be represent ed by the equation

$$
a=\frac{0.020}{T},
$$

where $a$ is the coefficient of linear expansion of a chemical element and $T$ is its melting point $\left({ }^{\circ} \mathrm{K}\right)$.

Wiebe [51] found the following relation between the coefficients of cubical expansion, specific heats, melting points, and atomie weights of the chemical elements that erystallize in the regular system:

$$
\alpha=\frac{1}{2.6 A c T}
$$

where $\alpha$ is the coefficient of eubical expansion, $A$ is the atomic weight, $c$ is the specific heat, and $T$ is the melting point ( $\left.{ }^{\circ} K\right)$. Since the coefficient of cubical expansion is three times the coefficient of linear expansion,

$$
a=\frac{1}{7.8 \cdot 4 T^{\circ}}
$$

Table 2 gives a comparison of the observed and computed coefficients of linear expansion of 28 chemical elements that showed a difference of less than $6 \times 10^{-6}$. These elements have bodycentered cubic, face-centered cubic, or hexagonal crystal structures (only one exception). The average difference between the observed and computed cocfficients of expansion of these elements is $\pm 2.1 \times 10^{-6}$. The differenees for other chemical elements on which data (atomic weight, specific heat, melting point, and coefficient of expansion) are available are eonsiderably greater than the diflerences indicated in the last column of table 2.

With the aid of the law of Petit and Dulong [52], which states that the product of the atomic weight and the specific heat of an element is approximately constant, Wiebe [53] transformed eq 36 into

$$
\alpha=\frac{1}{16.6},
$$

where $\alpha$ is the coeflicient of cubical expansion,

\begin{tabular}{|c|c|c|c|c|}
\hline Element & $\begin{array}{l}\text { Crystal } \\
\text { strue- } \\
\text { ture a }\end{array}$ & $\begin{array}{l}\text { Observed } \\
\text { coelficient } \\
\text { of linear } \\
\text { exprision. } \\
201^{\circ} \text { to } \\
100^{\circ} \mathrm{C}\end{array}$ & $\begin{array}{l}\text { Computed coeth- } \\
\text { cimnt of lineal ox- } \\
\text { mansion } \\
(a=-8.8 .5)^{b}\end{array}$ & $\begin{array}{l}\text { Dilfer- } \\
\text { encer }\end{array}$ \\
\hline $\begin{array}{l}\text { Aluminum... } \\
\text { Cidmium } \\
\text { Calcium } \\
\text { Cfuromium } \\
\text { Cobalt }\end{array}$ & $\begin{array}{l}\text { F } \\
\text { II } \\
F(11) \\
B(11) \\
H(\text { F })\end{array}$ & $\begin{array}{c}\times 10-6 \\
23.8 \\
31.8 \\
\times 22 \\
6.6 \\
12.6\end{array}$ & $\begin{array}{r}\times 111-85 \\
22.5 \\
34.9 \\
18 \\
9.9 \\
12.5\end{array}$ & $\begin{array}{l}\times 10^{-6} \\
+1.3 \\
-3.1 \\
+1 \\
-3.3 \\
+ \text { +i. } 1\end{array}$ \\
\hline $\begin{array}{l}\text { Copper..... } \\
\text { frold } \\
\text { lridimn } \\
\text { lron } \\
\text { Load }\end{array}$ & $\begin{array}{l}\mathrm{F} \\
\mathrm{F} \\
\mathrm{F} \\
\mathrm{F}\end{array}$ & $\begin{array}{r}16.8 \\
14.1 \\
6.8 \\
12.2 \\
29.1\end{array}$ & $\begin{array}{r}16.2 \\
15.7 \\
7.6 \\
11.8 \\
34.4\end{array}$ & $\begin{array}{r}+.6 \\
-1.6 \\
-0.8 \\
+.4 \\
-5.3\end{array}$ \\
\hline $\begin{array}{l}\text { Lithium } \\
\text { Magnesium } \\
\text { Molybdenum. } \\
\text { Nickel.... } \\
\text { Osminm }\end{array}$ & $\begin{array}{c}\mathrm{B} \\
\mathrm{H} \\
\mathrm{B} \\
\mathrm{H}(\mathrm{F}) \\
\mathrm{H}\end{array}$ & $\begin{array}{r}56 \\
2 f .0 \\
5.2 \\
13.3 \\
06.1\end{array}$ & $\begin{array}{r}51 \\
22.9 \\
7.1 \\
11.3 \\
7.3\end{array}$ & $\begin{array}{l}+5 \\
+3.1 \\
+1.9 \\
+2.0 \\
-1.2\end{array}$ \\
\hline $\begin{array}{l}\text { Palladinm -. } \\
\text { Plittinumt ... } \\
\text { Rhodiunt... } \\
\text { Ruthenium . } \\
\text { Selenium ... }\end{array}$ & $\begin{array}{l}\mathrm{F} \\
\mathrm{F} \\
\mathrm{F} \\
\mathrm{H} \\
\mathrm{H}\end{array}$ & $\begin{array}{r}11.1 \\
9.1 \\
\times .3 \\
09.1 \\
037\end{array}$ & $\begin{array}{l}11.1 \\
10.0 \\
0.3 \\
7.5 \\
39\end{array}$ & $\begin{aligned} & 0.0 \\
- & -.4 \\
-1.0 & +1.6 \\
-2 & -2\end{aligned}$ \\
\hline $\begin{array}{l}\text { Silver' } \\
\text { Sulfur } \\
\text { Tant:tum } \\
\text { Thorium } \\
\text { Titanium }\end{array}$ & $\begin{array}{c}\mathrm{l} \\
\mathrm{O} \\
\mathrm{B} \\
\mathrm{F} \\
\mathrm{H}(\mathrm{B})\end{array}$ & $\begin{array}{r}19.6 \\
064 \\
6.6 \\
11.3 \\
8.8\end{array}$ & $\begin{array}{l}17.2 \\
5.9 \\
1.0 \\
9.5 \\
9.0\end{array}$ & $\begin{array}{l}+2.4 \\
+5 \\
+0.6 \\
+1.8 \\
-0.2\end{array}$ \\
\hline $\begin{array}{l}\text { Tungsten } \\
\text { Vanıdium. } \\
\text { Zirconium.. }\end{array}$ & $\stackrel{\stackrel{B}{B}}{\text { II }(B)}$ & $\begin{array}{l}\frac{4.3}{\text { c }}+8.8 \\
5\end{array}$ & $\begin{array}{l}5.4 \\
10.9 \\
10.5\end{array}$ & $\begin{array}{l}-1.3 \\
-3.1 \\
-5.5\end{array}$ \\
\hline
\end{tabular}
and $T$ is the melting point $\left({ }^{\circ} \mathrm{K}\right)$.
TABLE 2. Comparison of observed and romputer (eq 37) coefficients of linear expansion of 28 elements

a $\mathrm{B}=$ body-centered culic; $\mathbf{F}=$ face-centered cutic; $\mathbf{H}=$ close-packet hexagonal; $O=$ or thor hombie. The designation in parenthesis indicates a modifcation at higher temperatures.

b In this equation, $q=$ coefficient of linear expansion, $\Lambda$ =atomic weight,

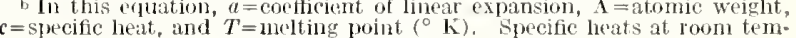
perature were used in computing the values given in this column.

o At $20^{\circ} \mathrm{C}$.

d From $25^{\circ}$ to $100^{\circ} \mathrm{C}$

If the cocflicients of linear expansion (at room temperature or for the range from $20^{\circ}$ to $100^{\circ}$ C) versus the atomic numbers of the chemieal elements are plotted, the periodic eurve shown in figure 25 is obtained. Lithium, sodium, phosphorus, potassium, rubidium, iodine, and cesium appear at the maxima of the curve. Carbon, silicon, chromium, molvbdenum, and tungsten are some of the elements that appear at the minima of the eurve. A similar relationship is obtained if the products of the atomic volumes ${ }^{3}$ and the coefficients of linear expansion versus the atomic numbers are plotted.

Cork [54] gives an equation for the difference of the specifie heats of solids at constant pressure and constant volume. This equation may be written as follows:

$$
a=\frac{1}{3} \sqrt{\frac{\left(C_{p}-C_{n}\right) \cdot J}{\epsilon T}}
$$

where $a$ is the coefficient of linear expansion at $T^{\circ} \mathrm{K}, \mathrm{C}_{p}$ is the specific heat at eonstant pressure, $C_{v}$ is the specifie heat at constant volume, $J$ is

${ }^{3}$ The atomic volume of a chemicul element is equal to its atomic weight divided by its density. 
the mochanical equivalent of heat, $e$ is the coefficient of volume chasticity or bulk modulus, and $V$ is the volume oceupicel by a gram or a grammole of the material (dopending whether the specifie heat at constant pressure is per gram or per gram-mole).

From available data on right metals, Pieted [55] in 1879 derived a ledation between thermal expansion, melting point, drisity, and atomic weight. The folkwing equation was derived in 1947 from available data on the body-centered cubic and face-centered cubic dements exept the alkali motals:

$$
a=\frac{0.0465 \sqrt[3]{d}}{T}
$$

where $a$ is the coefficient of linear expansion, $d$ is the density $\left(\mathrm{g} / \mathrm{cm}^{3}\right), A$ is the atomic weight, and $T$ is the molting point $\left({ }^{\circ} \mathrm{K}\right)$. Table 3 gives a comparison of the observed and computed coefficients of linear expansion of these body-eentered and face-centered cubite clements. Calcium, chrominm, and manganese show large differences between the observed and computed coeffieients of expansion. The average difference between the observed and computed coeflicients of expansion of the 19 clements is $\pm 2.5 \times 10^{-6}$.

In connection with an investigation of bondng between plasties and metals, 'Tumer [56] developed the following formula for the coefficient of cubical expansion, $\alpha_{T}$, of a mixture in terms of the coeflicients of cubical expansion, $\alpha$, fraction

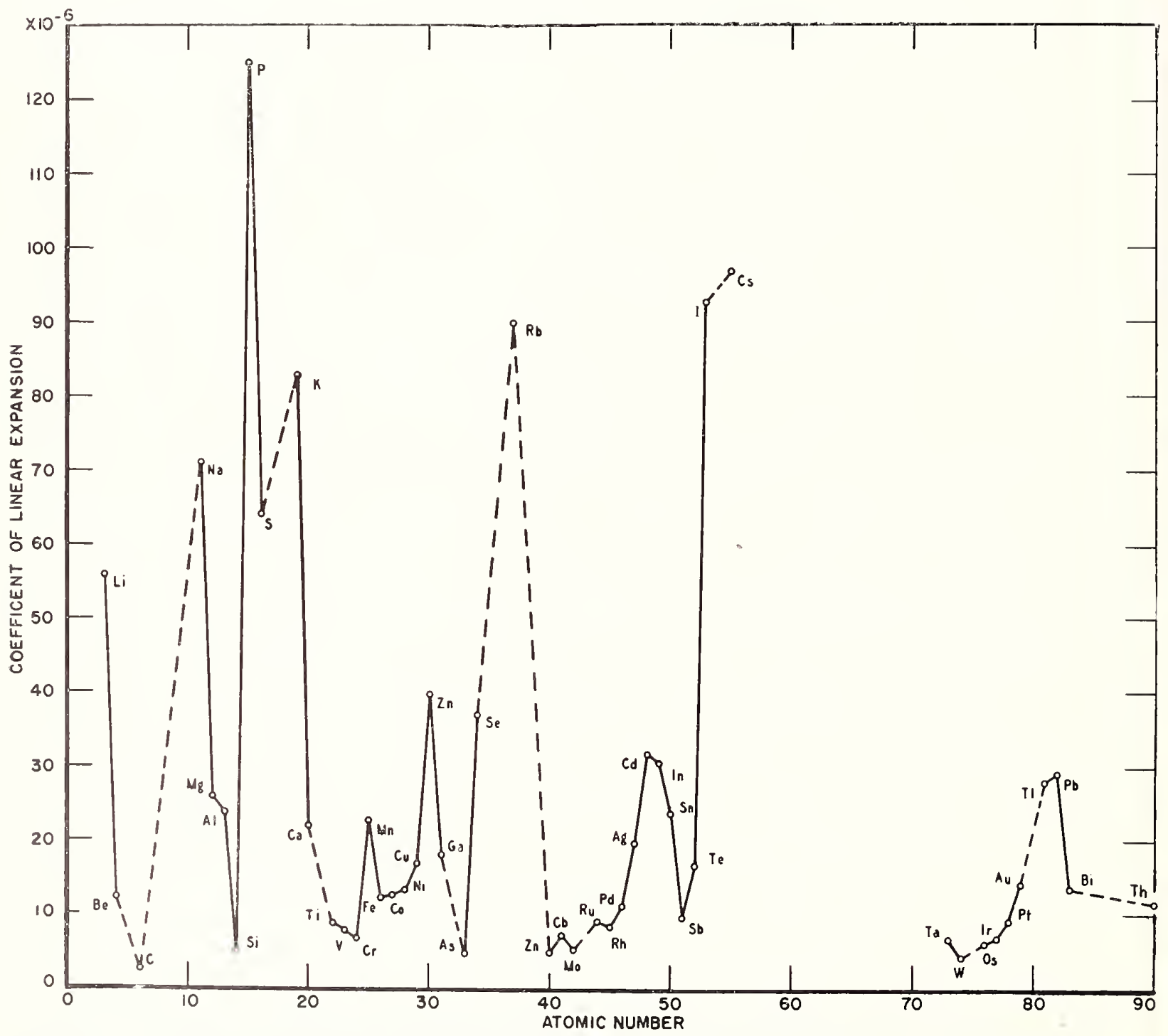

FIGURE 25. Relation between coefficients of linear thermal expansion (at room temperature or for the range from $20^{\circ}$ to $100^{\circ} \mathrm{C}$ ) and atomic numbers of chemicul elements. 
TABLE 3. Comparison of observed and computed (eq 40 ) coeffieients of body-eentered eubic and face-centered eubic elements (exeept alkali metals)

\begin{tabular}{|c|c|c|c|c|}
\hline Element & $\begin{array}{c}\text { Crystal } \\
\text { struc- } \\
\text { ture a }\end{array}$ & $\begin{array}{l}\text { Observed } \\
\text { coefficient } \\
\text { of linear } \\
\text { expansion, } \\
20^{\circ} \text { to } \\
100^{\circ} \mathrm{C}\end{array}$ & $\begin{array}{l}\text { Computed coelli- } \\
\text { cient of linear ex- } \\
\text { pansion } \\
\left(a=\frac{0.0465 \sqrt[3]{\frac{d}{1}}}{T}\right)^{b}\end{array}$ & $\begin{array}{l}\text { bitlier- } \\
\text { ence }\end{array}$ \\
\hline $\begin{array}{l}\text { Aluminum } \\
\text { Calcium } \\
\text { Chromium } \\
\text { Columbium } \\
\text { Copper.... } \\
\end{array}$ & $\begin{array}{c}F \\
F(11) \\
B(I I) \\
B \\
F\end{array}$ & $\begin{array}{r}\times 10^{-0} \\
23.8 \\
\times 22 \\
6.6 \\
\text { a } 7.2 \\
\text { e16.8 }\end{array}$ & $\begin{array}{r}23.1 \\
11.0 \\
11.4 \\
9.2 \\
17.8\end{array}$ & $\begin{array}{r}\times 10^{-6} \\
+11.7 \\
+8.0 \\
-5.0 \\
-2.19 \\
-1.0\end{array}$ \\
\hline $\begin{array}{l}\text { Gold } \\
\text { Iridium } \\
\text { Iron } \\
\text { Learl } \\
\text { Manganese. }\end{array}$ & $\begin{array}{c}F \\
F \\
B(F) \\
F(T) \\
B(T)\end{array}$ & $\begin{array}{r}14.1 \\
6.8 \\
12.2 \\
29.1 \\
22.8\end{array}$ & $\begin{array}{r}16.0 \\
8.3 \\
13.4 \\
29.1 \\
15.6\end{array}$ & $\begin{array}{l}-1.9 \\
-1.5 \\
-1.2 \\
-0.3 \\
+7.2\end{array}$ \\
\hline $\begin{array}{l}\text { Molybdenum } \\
\text { Palladium } \\
\text { Platinum } \\
\text { Rhodium } \\
\text { Silver } \\
\end{array}$ & $\begin{array}{l}\mathrm{B} \\
\mathrm{F} \\
\mathrm{F} \\
\mathrm{F} \\
\mathrm{F}\end{array}$ & $\begin{array}{r}5.2 \\
11.1 \\
9.1 \\
8.3 \\
19.6\end{array}$ & $\begin{array}{r}7.4 \\
12.3 \\
16.9 \\
16.3 \\
17.3\end{array}$ & $\begin{array}{l}-2.4 \\
-1.2 \\
-1.8 \\
-2.0 \\
+2.3\end{array}$ \\
\hline $\begin{array}{l}\text { Tantalum } \\
\text { Thorium.... } \\
\text { Tungstell.. } \\
\text { Vanadium . }\end{array}$ & $\begin{array}{l}13 \\
1 \\
13 \\
B\end{array}$ & $\begin{array}{r}6.6 \\
11.3 \\
4.3 \\
7.8\end{array}$ & $\begin{array}{r}6.4 \\
\times .2 \\
6.0 \\
11.1\end{array}$ & $\begin{array}{l}+0.2 \\
+3.1 \\
-1.7 \\
-3.3\end{array}$ \\
\hline
\end{tabular}

a $\mathrm{B}=$ bod $\mathrm{\gamma}$-centered cubic; $\mathrm{F}=$ face-centered cubic; $\mathrm{I}$ =close-packed hexgonal: $T=$ face-centered tetragonal. The designation in parentheses indicat agonal: $T=$ fact-centered tetragonal. The a modifieation at higher temperatures,

weight, and $T=$ melting point $\left({ }^{\circ} \mathrm{K}\right)$

c At $20^{\circ} \mathrm{C}$

From $0^{\circ}$ to $100^{\circ} \mathrm{C}$

From $25^{\circ}$ to $100^{\circ} \mathrm{C}$

or percentage by weight, $P$, bulk modulus, $K$, and density, $d$, of the individual components:

$$
\alpha_{r}=\frac{\frac{\alpha_{1} P_{1} K_{1}}{d_{1}}+\frac{\alpha_{2} P_{2} K_{2}}{d_{2}}+\cdots+\frac{\alpha_{n} P_{n} K_{n}}{d_{n}}}{\frac{P_{1} \Lambda_{1}}{d_{1}}+\frac{P_{2} K_{2}}{d_{2}}+\cdots+\frac{P_{n} K_{n}}{d_{n}}} .
$$

If the coefficients of cubical expansion of all components are equal to the same constant times their coefficients of linear expansion, then $a$ can be substituted for $\alpha$ in eq 41 to obtain

$$
a_{r}=\frac{\frac{a_{1} P_{1} K_{1}}{d_{1}}+\frac{a_{2} P_{2} K_{2}}{d_{2}}+\cdots+\frac{a_{n} P_{n} K_{n}}{d_{n}}}{\frac{P_{3} K_{1}}{d_{1}}+\frac{P_{2} K_{2}}{d_{2}}+\cdots+\frac{P_{n} K_{n}}{d_{n}}},
$$

where $a$ is the coefficiont of linear expansion.

Equation 41, based on stress equilibrium, reduces to a percentage by volume calculation if the ingredients have the same bulk moduli. If the ingredients have the same modulus to weight ratios, the calculation amounts to a percentage by weight interpolation.

The size and shape of the filler particles in plastic mixtures have an effert on the resultant coefficient of expansion of the mixture. Equations 41 and 42 do not take this phenemenon in to consideration. Difficulty is also encountered because the bulk motuli of some materials are not available. To solve these problems, eq 41 and 42 may be modified by substituting an cmpirically determined constant $C$ for $K / d$ for each material. Constant $C$ is interpreted as proportional to the modulus-density ratio rather than being equal to it.

For a mixture with components having nearly efual values of Poisson's ratio the bulk moduli are nearly proportional to the corresponding Young's moduli. For such mixtures Young's modulus, E, may therefore be substituted for bulk modulus in eq 42 to yield the following expression for the coefficient of linear expansion of a mixture:

$$
a_{\tau}=\frac{\frac{a_{1} P_{1} E_{1}}{d_{1}}+{ }^{a_{2} P_{2} E_{2}}+\cdots+\frac{a_{n} P_{n} E_{n}}{d_{n}}}{P_{1} E_{1}+\frac{P_{2} E_{2}}{d_{1}}+\cdots+\frac{P_{n} E_{n}}{d_{n}}}
$$

Thus, in many cases where the bulk moduli are not available, eq 43 may be used instead of eq 42.

\section{Applications of Thermal Expansion}

The problems in which the thermal expansion of materials must be recognized are as varied as our industries. The precision chronometer is useless without proper temperature compensation. The elaborate suspension bridge earrying thousands of tons of traffic hourty would be unsafe if in its design and construetion provisions for changes in dimensions of its member's incident to temperature changes had not been made. Precision instruments such as indieators for measuring lengths, composed of parts having differing expansivities may give erratic indications unless the temperat ure is maintained constant.

One of the most important uses of thermal expansion is in thermostats of various types (differential expansion, bimetallic flexure, and fluid expansion). 'Thermostats may be used in actuating circuit controllers for electrical devires such as electric furnaces, dectric irons, eleetric refrigerators, vulcanizers, alarm tevices, and stack controls, in the operation of mechanical controls such as means for regulating the flow of gas to gas ovens, and in pyrometers for indicating temperatures.

\section{Thermostats by Differential Expansion}

A large differential thermal expansion between two materials offers a basis for controlling and indicating temperature over a useful temperature range. For example, the change may be linear by 
plateing one material within the other, as an ahuminum rod within a fuserl-cpnartz tube. If the two materials are attached at one end and heatel or cooled, a clifferential motion is obtained at the othere ent. The linear motion may be converted into angular movement that may be magnified merhanically, if necessary.

\section{Thermostats by Bimetallic Flexure}

Thermostat motal (or himetal) may be prepared from two strips of metals or allivs having wirlely diflerent coofficionts of expansion, by wehling the strips throughout their entire leneth. lleating or cooling a thermostat metal prodheos a change of chrvature of the themostat motal, as indieated in figure 26. Heatime a straght narew piece of thermestat metal will cause it to bend and form an alre of a cincle with the lowapandinge motal on the immer site. Conversoly, if the straight namow piere of thermostat metal is cooled, the high-expanding metal will be on the imer side of the ale of a rincle. The action raused by the ehange of eluratume of themostat. metal rain be converted into a lincale or ancenlar" movement.

Commercial trpes of thermostat metals are arailable for valious temperature langes betwore $-500^{\circ}$ and $+1,200^{\circ} \mathrm{F}\left(-46^{\circ}\right.$ amb $\left.+649^{\circ} \mathrm{C}\right)$. There thermostat metals may he chassified as "fowtemperature" and "high-temperature"types. The low-tomperature group ineludes invar in eombination with brass or bronze. The high-temperature group inchudes all those themostat metals that ean be used at higher temperatures than those usme hass or hrome. For high-temperature use, frass or bronze has been replated by stronger alloys such as nickel-ropper alloys and nickel-hromium stainless alloys, to increase the temperature range of miform deflection. It is clesiralile that the thermal expansion and contraction of the metals or alloys selected for use in a thermostat metal, should be reversibte on heating and cooling in the temperature range in which the themostat metal can be subjected in tIse, in shipment, and in the process of mounting hy welding, soldering, or brazing. Thermostat notal should be properly heat treated in orelere to lolieve intcrnal stresses set up during the working and folming of the metal.

The funclamental relation between tho properties of the two metals or alloys (uements 1 and 2) of a narow themostat inctal when heated or cooled, may be expressed by the equation ${ }^{5}$

$$
\frac{1}{R}=\frac{6(\Delta a)(\Delta T)\left(t_{1}+t_{2}\right) t_{1} t_{2} E_{1} E_{2}}{3\left(t_{1}+t_{2}\right)^{2} t_{1} t_{2} E_{1} E_{2}+\left(t_{1} E_{1}+t_{2} E_{2}\right)\left(t_{1}^{3} E_{1}+t_{2}^{3} E_{2}\right)},
$$

\footnotetext{
4 A flat. wide strip of thermostat motal when heated or cooled will assume the shape of a portion of a curved tube

8 The equations in this subsection were obtaines from eatalog 1925 edition) by the H. A. Wilson Co., Newark, N. J. and publieation by Hood [57].
}

where

$R=$ radius of curvature of thermostat metal

$\Delta a=$ difference in roefficients of expansion of elements 1 and 2

$\Delta T=$ differenee in temperature

$t_{1}=$ thickness of plement 1

$t_{2}=$ thickness of alement 2

$E_{1}=$ elastir modulus of element 1

$E_{2}=$ elastic modulus of clement 2 .

When the elastic moduli are equal, of (44) reduces to

$$
R^{1}=\frac{6(\Delta a)(\Delta T) t_{1} t_{2}}{\left(t_{1}+t_{2}\right)^{3}}
$$

When the clastie moduli are equal and $t_{1}=t_{2}$, "qu 44 reduces to

$$
\frac{1}{R}=\frac{3(\Delta a)(\Delta T)}{2 t}
$$

where $t$ is the total thickness of the thermostat metal.

The coeffieients of thermal expansion and the Mastic moduli of most materials are not miform over wite temperature langes. For a limited temperature range the curvature an be expressed by the ergution

$$
\frac{1}{R}=\frac{2 k(\Delta T)}{l}
$$

where $k$ is a constant tepending on the difference in the cocflicients of thermal expansion and on the ratio of the elastic morluli of the two elements.

For a narow straight strip of thermostat metal fastened at one rud ant fies to move at the other ent, the deflection or distance moved by the free end may be represented approximately by

$$
d=\begin{gathered}
L^{2} \\
2 R^{\prime}
\end{gathered}
$$

where $d$ is the deflection and $L$ is the offective length of the strip. If the value of $\frac{1}{R}$ from eq 47 is substituted in oq 48, the following rquation is obtainerl for the deflection:

$$
d=\frac{k(\Delta T) L^{2}}{t} .
$$

If the narrow strip of thermostat metal is shaped in the form of a $U$ with arms of equal length, the deflection of the free end is given by

$$
d=\frac{k(\Delta T) L^{2}}{2 t}
$$

where $L$ is the developed length of the strip. 


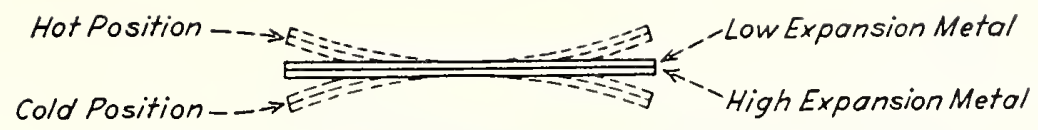

Figure 26. Effect of heating and cooling thermostat metal (IIood).

For thermostat metal shaped in the form of a circular ring, the deflection of the free end is

$$
d=\frac{k(\Delta T) L^{2}}{\pi t},
$$

where $L$ is the developed length of the ring. This shape is used for restricted spaces in which auxiliary arns or levers are employed to obtain additional motion.

The foree exerted at the end of a straight strip of thermostat metal fastened at one end and touching a stop at the other end may be represented by

$$
P=\frac{k(\Delta T) w t^{2} E}{4 L},
$$

where $P$ is the force, and $w$ is the width of the strip.

For a thermostat metal in the form of a helix or spiral, the angular rotation between the ends may be obtained approximately from the following equation:

$$
\Theta=\frac{360 k(\Delta T) L}{\pi t},
$$

where $\theta$ is the angular rotation in degrees. The torque of a coil is

$$
M=\frac{k(\Delta T) w t^{2} E}{6},
$$

where $M$ is the torque.

Thermostat metal is also used in the form of a round disk pressed into a concave or convex shape so that on heating or cooling, the disk will buckle from one side to the other'.

Figure 27 shows some of the shapes of themostat metals. Additional information about these materials may be obtained from manufactures of thermostat metals.

Methods of testing thermostat metals have been published by American Society for Testing Materials [58].

\section{Thermostats by Fluid Expansion}

The larece cubical thermal expansion of some liquids and gases has been applied for thermostats and for pyrometers. In the mercurial thermostat the contact is mate by the mercury column, which rises when heated and contacts electric wines embedded in the glatss and projecting into the capillary tube. Another type of liquid thermostat consists of a bulb, capillary tube, and bellows filled with a suitable liquid. The expansion or contraction of the liquid on lieating $01^{\circ}$ cooling actuates the bellows. The mercurial thermometer is the most common application for indicating temperature. 'The tin pyrometer' is another application in which a chemical element in the liquid state has been used in the measurement of high temperatures.

Gas-filled thermostats have wider application than liquid-filled thermostats on account of the greater temperature range of the former. The sensitive bulb may be comnected by capillary tubing to a Bourdon tube spring wound into the form of a helix. When the thermostat is heated, the gas expands and exorts a pressure that causes the spring to unwind. In some fire-alarm systems, the operation depends on the expansion of air from the heat of the fire or air within a vent-compensated system, which deflects diaphragms forming one side of connected air cells to make an electrical contact instrumental in sounding the alarm. The operating pressure and vent are so adjusted that pressures built up from ordinary temperature changes will not cause false operation of the system. The air volume concerned can be contained in long runs of fine tubing or can be consoliclated in clusters of tubing or in bulbs of relatively large volume.

A thermostat using other vapor in a balanced mereury column system, similar to that described by Green and Loring [59] is used in the gage block constant-temperature room of the National Bureau of Standards and has been found to be highly sensitive. Green and Loring's thermostat bulb las been replaced by a spiral to increase the sensitivity. A displacement of $1 / 2 \mathrm{in}$. corresponds to a change of about $1^{\circ} \mathrm{C}$. 


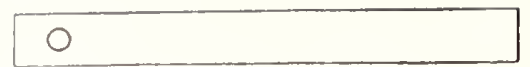

(1) STRIP

\section{(1)}

\section{(2) HAIR PIN}

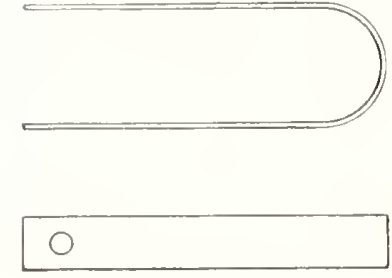

(3) U-SHAPE

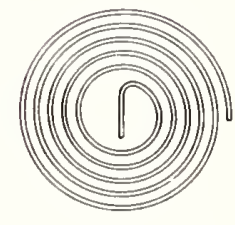

(4) SPIFAL

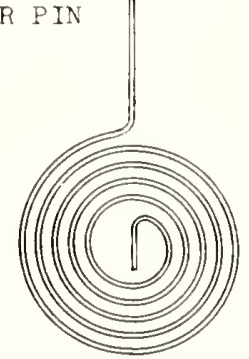

(5) SPIRAL
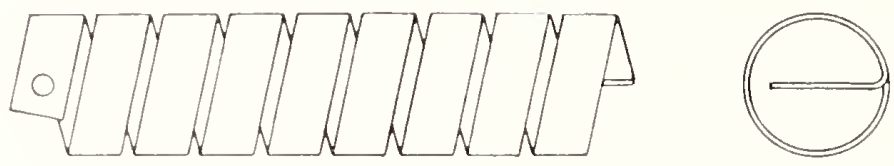

(6) HELIX (LEFT HAND WOUND)
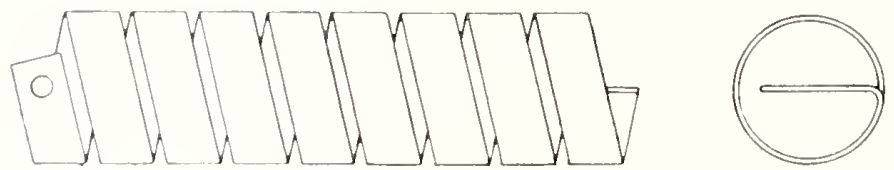

(7) HELIX (RIGHT HAND WOUND)

Figure 27. Typical shapes of thermostat motal (Catrlog, W. M. Chare Co., 1934).

\section{References}

[1] P. Hidnert, Themal expansion of copper and some of it important industrial alloys, Rei. Pap. Bs 17, !1 (1922) $\$+10$.

[2] IV. Fonder and P. Hidnert, Measmements on the thermal expansion of fliser siliea, hei. Pap. BS 21 , $1(1926-27) \div 524$.

[3] H. Luckiesh, L. I. IIotharlay and R. H. Sinden, An interference thelmometel and hilatometer combined, J. Franklin Inst. 194, 251 (1922).

[4] 6. L. Mrritt, The interference mothor of measuring thermal expansion, BS J. Rescalch 10,59 (1933) 12.5515.

[5] J. B. Austin, I vacum apparatus for measuring thermal expansion at clerater temperatures, with measnements on platimnn, gold, magnesinm and zine, Physics 3, 240 (1!32).

[6] C. C. Peters and C. II. Cragoe, Measurements on the themal dilatation of glass at high temperatures, Sci. Pap. BS 16, $44 !$ (1920) S393.

[7] J. B. Saunders, Improved interferometric procedure with applicafion to expansion measurements, J. Rescarch NBS 23, 17! (1939) RP1227.

[8] A. Trowbridge, Photography of moving interference fringes, J. Opt. Soc. Ant. of, 195 (1922).
[9] M. 1. Amulf, Un apparcil curegistreur pour la mesure des dilatations dox verese Rev optique 3, 270 (1!24).

[10] R. I1. Sinden, An intorferential dilatometer employing automatic photography, J. Opt. Soc. An. 15, 171 (1!127).

[11] F. ( Nix and D. Mac Nair, Interferometric dilatometro with photographic recosding, Rev. Sci. Instr. 12, $60(1941)$.

[12] J. B. Saunclers, In apparatus for photographing interfrrence phenomena, J. Research NBS 35, 157 (1945) R.'1668.

[13] W. F. Meggers, Notes on comparisons of lengths of hight waves by interference methods, and some wave lengths in the spectrum of neon gas, sci. Pap. BS 12, $198(1915-16)-251$.

[14] C. G. Peters, The isse of the interforometer in the measurement of small dilatations or differential dilatations, J. Wash. Lead. Sci. 9, 281 (1919).

[15] L. A. Willey and IV. L. Fink, An interferometer type of dilatometer, and some typical resilts, Trans. Im. Fust. Min. Met. Eng., Iron \& Steel Div, 16\%, 642 $(1 ! 45)$.

[16] P. Hidnert and IV. T. Sweeney, Thermal expansion of magnesimm and some of its alloys, BS J. Research 1, 771 (1928) RP29.

Circulars of the National Burean of Standards 
[17] P. Iidnert, Thermal expansion of monoerystalline and polycrystalline antimony, J. Researeh NIBS 14, 523 (1935) RP784

[18] P. Hidnert and G. Dickson, Some physical properties of mica, J. Research NBS 35, 309 (1945) RP1675.

[19] F. M. Walters, Jr. and M. Ciensamer, Alloys of iron, manganese and carbon-Part IV. A fliatometric study of iron-manganese binary alloys, Trans. Am. Soc. Steel Treating 19, 608 (1932).

[20] W. E. Kingston, A new type of recording dilatometer, Metal Progress 44, 1115 (1943)

[21] W. Soucler, P. Hidnert and J. F. Fox, Autoglaplic thermal expansion apparatus, J. Reveareh NBS 13, 497 (1934) RP722.

[22] P. Chevenard, Nouveau modèle d'analyseur thermique industriel, Revue de Métallırgie 19, 39 (1922); Dilatomètre différential à enregistrement mécanique, Revte de Métallurgie \$3,92 (1926); and Dilatomètres enregistreurs, J. Physique et Radium \%,240 (1926).

[23] J. II. Andrew, J. L. Rippon, C. P. Miller and I IV ragg, The effect of initial temperature upon the physical properties of steel, J. Iron and SteeI Institute 101, 527 (1920).

[24] J. I. Haughton and W. T. Griffiths, some uses of the threarl recorder in the measurement of physical properties, J. Sci. Instruments 1, 225 (1924).

[25] R. A. IIeindl, The thermal expansion of refractorics to $1,800^{\circ}$ C, BS J. Research 10, 715 (1933) RP562.

[26] W. E. Prytherch, A new form of dilatometer, J Sci. Instruments 9, 128 (1932).

[27] J. I. Ilaughton and F. Adeock, Improvements in Prytherch's capacity dilatometer, J. Sci. Instruments 10, $178(1933)$

[28] W. II. and W. I. Bragg, The reflection of X-rays by crystals, Proc. Roy, Soc. 88, 428 (1913).

[29] A. II. Hull, A new method of X-ray erystal analysis, Phys. Rev. 10,661 (1917).

[30] P. Debye and P. Scherrer, Interferenzen an regellos orienticrten Teilchen in Röntgenlicht, III, Phys. 7. 18, 291 (1917)

[31] J. D. IIanawalt and L. K. Frevel, X-ray measurement of the thermal expansion of magnesium, $Z$. Krystallogr. 98, 84 (1937)

[32] G. Shinoda, X-ray investigations on the thermal expansion of solids, Part 2, Mem. College of Scienee, Ii voto Imp. Univ., Series $\Lambda, \mathbf{1 7}, 27$ (1934).

[33] K. Becker, Eine röntgenographische Methode zur Bestimmung des Wärmeausdehnungskoeffizienten bei hohen Temperaturen, Z. Physik 40, 37 $(1926-27)$

[34] A. H. Jay, A high temperature X-ray camera for quantitative measurements, Z. Líristallogr. 86, 106 (1933), and A high-temperature X-ray camera for precision measurements, Proc. Pliys. Soc. London 45, 635 (1933).

[35] A. J. C. Wilson, The thermal expansion of aluminum from $0^{\circ}$ to $650^{\circ} \mathrm{C}$, Proc. Phys. Soc. London $\mathbf{5 3}$, 235 (1941).

[36] G. Shinoda, X-ray investigations on the thermat expansion of solids, Part 1, Mem. College of Science, Kyoto Imp. Univ., Series A, 16, 193 (1933).

[37] A. Matthiessen, On the expansion by heat of water and mercury, Phil. Trans. Royal Soc. London 156, 231 (1866)

[38] A. Matthiessen, On the expansion by heat of metals and alloys, Phil. Trans. Royal Soc. London 156, $861(1866)$
[39] J. Dewar, Coefficients of the cubical expansion of ice, hydrated salts, solid carbonic aeid, and other substances at low temperatures, Proc. Roy. Soc. London 70, 237 (1902).

[40] C. M. Sacger, Jr., and F.J. Ash, A method for tletermining the volume cluanges occurring in metals during casting, 13- J. Research 8, 37 (1932) liP399. and Tethors for determining the volume changes undergone by metals and alloys cluring casting, Trans. An. Foundrvmen's Assoc. 38, 107 (1930).

[41] P. Hidnert, Thermal expansion of aluminum and various important aluminum alloys, BS Sci. P'ap. 19, $697(1923-24) \quad S 497$

[42] J. D. Edwards and F. A. Moormann, Density of aluninum from $20^{\circ}$ to $1,000^{\circ} \mathrm{C}$, Chem. \& Iet. Eng. 24, 61 (1921).

[43] R. J. Anderson, Linear contraction and shrinkage of a series of light aluminum allovs, Trans. Am. Foundrymen's Assoc. 31, 392 (1923).

[44] R. L. Coleman, Physical properties of dental materials (gold alloys and accessory materials), BA' J. Research 1, 867 (1928) RP32.

[45] Derivation by IT. Souder, National Burcau of Standards (inot published).

[46] E. Grüneisen, Über die thermische Ausdehnung und die spezifische Wärme der Metalle, Ann. Physik ?6, 211 (1908).

[47] W. Hume-Rothery, On Grüneisen's cquation for thermal expansion, Proc. Phys. Soc, London 5y, 209 (1945)

[48] F. Simon and E. Vohsen, Kristallstrukturbestimmung der Alkalinctalle unel des Strontiums, $Z$. phys. Chem. 133, 165 (1928).

[19] T. Carnelley, Ueber die Bezichung zwischen den Sehmelzpunkten der Elemente mol ihren Ausdehnungscoëfficienten durch Wärme, Ber. deut. chem. Ges. 12, 439 (1879)

[50] M. Lémeray, Sur une relation entre la dilatation et la température de fusion des métaux simples, Comptes Rendus 131, $1291(1900)$

[51] H. F. Wiebe, Teber die specifische Wärme und die Ausdehnung der starren Elemente, Ber. deut. chem. Ges. 13, $1258(1880)$

[52] Petit and Dulong, Sur quelques points importants de la théoric de la chaleur, Ann. chim. phys. 10, 395 (1S19).

[53] H. F. Wicbe, Ueber die Beziehung des Schmelzpunktes zum Ausdehnungskoeffizienten fler starlen Elcmente, Verh. deut. phys. Ges. 8, 91 (1906).

[54] J. M. Cork, Heat, 2nd efl. (1942).

[55] R. Pietet, Démonstration théorique et expérincntale de la définition suivante de la température: La température est representée par la longueur de l'oscillation calorifique des molécules d'un corps, Comptes Rendus 88, 85.5 (1879).

[56] P. S. Turner, Thermal-expansion stresses in reinforeed plastics, J. Research NBS 37, 239 (1946) PP1745.

[57] R. S. Hood, Thermostat Metal, A. S. T. M. Standards on Electrical-Heating and Resistanee Alloys, p. 93 (January 1942).

[58] "Standard methods of testing thermostat metals," A. S. T. M. Designation B106-40, A. S. T. II. Standards on Electrical-Heating \& Resistance Alloys, Sept. 1941, p. 87.

[59] J. B. Green and R. A. Loring, A thermostat for room temperature control, Rev. Sci. Instruments 11, $\$ 1$ (1940).

WASHNGTON, April 4, 1949. 
